ISSN: $1130-2887$

\title{
UN ANÁLISIS DE LAS REFORMAS JUDICIALES DE ARGENTINA, CHILE Y URUGUAY Judicial reform in Argentina, Chile and Uruguay
}

\author{
ELIN SKAAR \\ Chr. Michelsen Institute de Bergen, Noruega \\ *elin.skaar@cmi.no
}

BIBLID [1130-2887 (2003) 34, 145-184]

Fecha de recepción: noviembre de 2002

Fecha de aceptación y versión final: enero de 2003

RESUMEN: Este artículo trata sobre las reformas judiciales en Sudamérica, durante los años 90. Muestra que tanto en el caso de la Argentina como en el de Chile, las reformas a los códigos de procedimiento estuvieron motivadas por tres factores centrales, vinculados con el doble proceso de democratización y liberalización económica: i) la preocupación con la violación de derechos humanos que provenía de los pasados regímenes autoritarios; ii) el deseo de crear ambientes legales estables tanto para los derechos de propiedad como para la inversión extranjera; y iii) la preocupación pública en torno a tasas de criminalidad cada vez más altas. Las reformas constitucionales que afectaron a las Cortes Supremas tanto en la Argentina como en Chile estuvieron vinculadas por razones estrictamente auto-interesadas. En última instancia, estas reformas fueron el resultado de compromisos políticos entre la izquierda y la derecha en respuesta a particulares eventos nacionales. En Uruguay, los frustrados intentos por desarrollar reformas en el código de procedimientos criminales y en el ámbito de la Corte Suprema pueden atribuirse a una combinación de falta de voluntad política, la carencia de apoyo a las mismas reformas judiciales, y una falta de recursos económicos. Notablemente, el análisis muestra que en ninguno de los tres países examinados las agencias internacionales han jugado un rol significativo a la hora de promover reformas u ofrecer asistencia financiera o técnica en favor de los cambios en los códigos de procedimiento o en la organización de las Cortes Supremas. Ello sugiere que estos dos tipos de reformas judiciales en el Cono Sur han sido motivados, ante todo, a partir de demandas nacionales, y no a partir de una presión internacional -lo que muestra una diferencia importante en el contexto de reformas que distinguió a estos tres países latinoamericanos-, y el que se dio en otros países de la región.

Palabras clave: reforma judicial, reforma en la Corte Suprema, Argentina, Chile, Uruguay. 
ABSTRACT: This article is about judicial reform in the Southern Cone in the 1990s. It shows that for Argentina and Chile, procedural code reforms were motivated by three central factors linked to the twin processes of democratisation and economic liberalisation: i) concern with human rights violations stemming from the past authoritarian regimes; ii) the desire to create a stable legal environment for property rights and foreign investment; and iii) public concern with rising crime rates. By contrast, constitutional reforms affecting the Supreme Courts in Argentina and Chile tended to be driven by narrow political self-serving interests. These reforms ultimately came about as the result of political compromises between the left and the right in response to particular catalytic national events. In Uruguay, unsuccessful attempts at both criminal procedure reform and Supreme Court reform may be attributed to a combination of a lack of political will, lack of support from the judiciary itself, and a lack of financial recourses. Interestingly, the analysis shows that in none of the three countries examined have international agencies of foreign donors played a central role in pushing for or offering financial or technical assistance to procedural code or Supreme Court reforms. This suggests that these two types of judicial reforms in the three Southern Cone countries have principally been driven by national demand rather than external pressure -which makes the context for reform different from that of many other Latin American countries-.

Key words: judicial reform, Supreme Court reform, Argentina, Chile, Uruguay.

\section{INTRODUCCIÓN ${ }^{1}$}

Durante la década de los 90, toda la región latinoamericana se ha visto barrida por reformas judiciales. Por lo menos dieciocho países han llevado adelante reformas más o menos sustantivas en su organización judicial ${ }^{2}$. Ellas incluyeron, por ejemplo, reformas vinculadas con la independencia judicial, la administración de justicia, códigos de procedimiento, el acceso a la justicia, el entrenamiento y la educación legal, y las asociaciones profesionales. En general, podríamos dividir estas reformas entre aquellas orientadas a incrementar la transparencia y la eficiencia del sistema judicial, y aquellas otras destinadas a modificar los poderes de la Corte Suprema. Por qué se han producido estas reformas, en contextos tan diferentes

Mi análisis comparativo del contexto postdictatorial en Argentina, Chile, y Uruguay, me permite ofrecer algunas respuestas tentativas a dicha cuestión. Concentraré mi análisis en dos tipos principales de reformas: 1) las vinculadas con los códigos de procedimiento $^{3}$ y 2) las orientadas a incrementar la independencia judicial a través de cambios introducidos en la estructura de la Corte Suprema. Argentina y Chile

1. Una primera versión de este artículo fue presentada en el XIII Congreso de la Latin American Studies Association en Washington DC, 6-8 de septiembre, 2001. Quisiera agradecer a Roberto Gargarella por traducir este texto desde el inglés al español.

2. Para una buena revisión de las reformas judiciales desarrolladas en América Latina ver, por ejemplo, Buscalgia (1995); Dakolias (1995); Dakolias (1996); FrÜHling (1998); Garro (1993).

3. Como fuentes adecuadas para evaluar las reformas en la justicia penal, pueden consultarse los informes y documentos preparados por el Banco Mundial, el Fondo Monetario Internacional (FMI), la Fundación Ford, la Agencia Norteamericana para el Desarrollo Internacional (USAID), los ministerios públicos nacionales (cuando existen) y diversos académicos. 
aparecen entre los principales reformadores de América Latina ${ }^{4}$. En contraste, Uruguay no ha tenido ningún intento exitoso de incrementar constitucionalmente la independencia de la Corte, ni ha modificado su código de procedimiento penal. En este escrito, intentaré explicar estas diferencias. A través de un análisis profundo basado en fuentes secundarias tanto como en entrevistas a jueces, abogados, académicos y otras figuras públicas en los tres países, trataré de desvelar algunas de las complejidades que han rodeado a estas reformas. En resumen, el escrito se propone mostrar que las diferentes reformas tenían fines también diferentes, tanto como causas diferentes, a la vez que implicaban grupos de actores diferentes.

Con el fin de examinar los cambios producidos en el sistema de justicia penal, prestaré atención a las medidas tendentes a reformar el Código Penal, modificar la división de trabajo entre los jueces y los fiscales, y crear los así llamados ministerios públicos. Con el objeto de examinar las reformas tendentes a incrementar la independencia judicial, he destacado cinco factores habitualmente mencionados en la literatura como indicadores claves de la independencia estructural de la justicias: i) procedimientos de designación ${ }^{6}$; ii) extensión del mandato de los jueces superiores ${ }^{7}$; iii) Consejos de la Magistratura $^{8}$; iv) medidas destinadas a incrementar los poderes de revisión judicial de la Corte Suprema, a través de la creación de Cortes Constitucionales u otros medios?;

4. Aquí me baso en las Constituciones de ambos países.

5. Ver, por ejemplo, DOMingo (1999); HAMMERGREN (1998); LARKINS (1996); WidNER (1999). Adviértase que no existe un acuerdo general en torno a la independencia judicial, en la literatura con la que contamos. Muchos académicos han tratado de desarrollar índices de independencia relativamente fiables, pero cada uno de ellos ha generado una tormenta de críticas. Dado que la tarea es relativamente nueva, queda mucho espacio para mejorar estas medidas. Espero, a través de mi análisis, realizar una modesta contribución en la materia. Ver RoSENN (1987), para un excelente recuento de los distintos intentos realizados tendientes a medir la independencia judicial, y los problemas propios de estos enfoques. Ver YAMANISHI (1999) para un buen repaso acerca de los índices que existen para medir la independencia judicial.

6. Los jueces en general, y los jueces de la Corte Suprema, en particular, no deben ser reclutados o removidos a voluntad del presidente.

7. La composición de la Corte debería mantenerse inmodificada de una Administración a la siguiente. Normalmente se considera que la designación de por vida es lo ideal, porque de ese modo los jueces tienen menos posibilidad de ser influidos por razones políticas en sus decisiones. De todos modos, como HelmKe (2002) argumenta de modo elegante para el caso de Argentina, puede ocurrir que situaciones de inseguridad en el cargo lleven a un incremento en la independencia de los jueces, que de ese modo tienen mayor voluntad de complacer a los futuros políticos que a los que se encuentran en ese momento en el gobierno.

8. Los Consejos de la Magistratura están, normalmente, aunque no siempre, compuestos por representantes provenientes de diversas instituciones públicas y privadas. Su propósito principal es el de elegir a los jueces. Al impedir que el Ejecutivo concentre la principal capacidad de nombramiento de los jueces, los consejos ayudan a crear tribunales menos dependientes.

9. Tanto como los Consejos de la Magistratura, las Cortes Constitucionales se han diseñado a la luz de las Cortes europeas. Su principal propósito es el de asegurar un freno a los abusos del Ejecutivo y el Legislativo. Una breve historia de la función de la revisión judicial en DOMINGO (1999); SCHWARTZ (1999). 
y v) el establecimiento de garantías destinadas a asegurar la independencia financiera de la justicia, lo que significa que un cierto porcentaje del presupuesto estatal queda garantizado a la propia justicia

Este escrito es fundamentalmente empírico ${ }^{10}$. Se espera que el análisis que sigue pueda aclarar algunas de las complejidades que rodean a la reforma judicial. De todos modos, el trabajo se encuentra guiado por tres hipótesis complementarias: 1) la reforma judicial está íntimamente conectada con los procesos de liberalización económica ${ }^{11}$;2) la reforma judicial tiene como motivo, además, cuestiones relativas a los derechos huma$\operatorname{nos}^{12}$; 3) la reforma judicial dirigida a incrementar los poderes de la Corte Suprema o a alterar su composición se ha debido fundamentalmente a intereses políticos más restringidos, particularmente en situaciones en donde se han producido cambios en el sistema de partidos o en la estructura tradicional de poder ${ }^{13}$. El artículo sostiene que tanto las reformas procedimentales como las realizadas al nivel de la Corte Suprema han sido iniciadas y promovidas por actores nacionales en los tres países bajo examen, y sin una influencia mayor por parte de las agencias internacionales. Ello distingue a los esfuerzos en pos de las reformas judiciales en estos tres países, de los que se dieron en otros países latinoamericanos, en donde el apoyo de las agencias internacionales -tales como el Banco Interamericano de Desarrollo, el Banco Mundial y USAID- ha sido mucho más significativo.

Comparando y contrastando estos dos tipos principales de reforma en estos tres países, trato de mostrar que las reformas constitucionales sobre la Corte Suprema han estado motivadas por intereses políticos estrechos, mientras que las reformas en los códigos de procedimiento se han debido a factores diferentes que incluyen, en general, a una diversidad de actores - mayores que los involucrados por las reformas sobre la Corte-. Estas explicaciones nos brindan una visión más completa que la que ofrece la literatura existente, frente a la pregunta: «por qué una reforma judicial?» ${ }^{14}$. Dado que el tema de la reforma judicial se encuentra actualmente en la agenda política de casi todos los países latinoamericanos (tanto como en Asia, África, Europa del Este y algunos países occidentales), este análisis pretende arrojar luz sobre las posibles causas de los esfuerzos de reforma de la justicia realizados, también, en otros contextos.

10. El mismo forma parte de un proyecto mucho más extenso, vinculado con mi tesis doctoral, destinada a evaluar las reformas judiciales, la independencia judicial, y los procesos legales seguidos contra militares, en razón de violaciones de derechos humanos. Ver SKAAR (2002).

11. DAKOliAS (1995); FinKel 1999; JARQUín 1998).

12. Correa Sutil (1993); Garro (1993); STOTZKY (1993).

13. Veáse el relativamente nuevo cuerpo de literatura, referido a reformas institucionales. Por ejemplo BoIX (1997); GEDDES (1990); GEDDES (1994); HAGGARD (1997); TsEBELIS (1990).

14. Por un lado, los teóricos de la democracia han defendido de modo unánime la independencia judicial en los procesos de consolidación democrática. Por ejemplo, ver BECKER (1999); FRANKEL (1993); Kahn (1993); Nino (1992); PlatTneR (1999b); STOTZKy (1993). Por otro lado, los economistas han señalado la importancia de la independencia judicial a los efectos de favorecer el libre mercado económico. Ver, por ejemplo, DAKOLIAS (1995); FINKEL (1999); JARQUín (1998). 
El escrito se organiza a partir de tres casos principales. En la segunda parte del mismo se ofrece un panorama de los sistemas judiciales existentes en los tres países. En la tercera parte se trata del caso argentino, las reformas a la justicia penal de 1993, y la reforma constitucional de 1994. La cuarta parte muestra los distintos intentos realizados en Chile por reformar el sistema judicial, incluyendo los cambios de los miembros de la Corte Suprema designados por el general Pinochet, y los referidos al sistema de justicia penal. En la quinta parte trato de explicar por qué las reformas no han prosperado en Uruguay -salvo una reforma en el Código de Procedimiento Civil, en 1989-. Finalmente, en la sexta parte, trato de ofrecer un resumen con comentarios y sugerencias destinados a orientar una investigación futura.

\section{Comparando los Sistemas Judiciales en el Cono SuR}

Argentina, Chile, y Uruguay (como una mayoría de países latinoamericanos) pertenecen a la tradición judicial del Derecho civil, que se basa en un sistema legal heredado del Derecho español. Comparten, por lo tanto, muchos rasgos en común. Ante todo, los tres países siguen una tradición de Derecho escrito, lo cual implica que toda la evidencia debe ser presentada a los jueces de modo escrito. En segundo lugar, los jueces actúan de modo habitual como fiscales y jueces, por lo que el juez resulta responsable tanto de la investigación como de la resolución del caso. En tercer lugar, el poder ejecutivo, tradicionalmente, ha dominado al poder judicial ${ }^{15}$.

A pesar de las similitudes señaladas, los sistemas judiciales de cada uno de tales países se encuentran organizados de modo diferente. En Argentina, la organización de la Corte sigue un principio federal. Cada provincia tiene sus propias Cortes de Apelación. La Corte Suprema se encuentra localizada en la capital del país. En Chile, cada una de las regiones tiene sus propias Cortes inferiores, pero no todas ellas tienen su Tribunal de Apelación. La Corte Suprema, como tribunal superior, se encuentra situada en Santiago ${ }^{16}$. En Uruguay, y dado el tamaño geográfico más reducido y su menor población, nos encontramos con que todas las Cortes de Apelación tanto como la Corte Suprema se encuentran localizadas en Montevideo. De todos modos, existen tribunales inferiores (civiles y penales) en cada distrito. Resulta típico dentro de la estructura judicial de estos tres países el carácter jerárquico de la judicatura. Las Cortes Supremas han ejercido, de modo habitual, una fuerte supremacía frente a los tribunales inferiores. Parte de las reformas han tenido como objeto reducir la dependencia de la Corte Suprema en relación con el Ejecutivo, tanto como reducir el control de la primera sobre los tribunales inferiores.

15. Mayor información en torno a este tipo de sistemas legales en los países latinoamericanos puede encontrarse en THOme (1998); VAughn (1992).

16. Un análisis completo de esta organización, en VARGAS (1995). 


\section{ARgENTINA}

\section{III.1. Introducción}

Argentina se ubica entre los principales países reformistas de América Latina. Este país ha llevado adelante dos tipos de reforma judicial, desde la vuelta a la democracia en 1983: una reforma en la justicia penal y una reforma referida a la Corte Suprema. Durante el primer gobierno democrático, liderado por el presidente del Partido Radical, Raúl Alfonsín, no se produjeron reformas más allá de las introducidas en el área de la justicia militar. Por contraste, durante el gobierno de su sucesor, Carlos Menem, se llevaron a cabo amplias reformas (Menem gobernó el país en los períodos 1985-1995 y 1995-2000). Antes de discutir cada una de estas reformas, conviene echar una mirada sobre el sistema de organización judicial argentino durante la dictadura militar y en el período de transición inmediatamente posterior.

\section{III.2. El sistema judicial durante el régimen militar y durante el periodo de transición}

Tras el golpe de Estado de 1976, las autoridades militares modificaron la composición de la Corte Suprema, cambiaron al procurador general de la nación, y así también a los miembros de las altas Cortes provinciales. Los militares quitaron de sus puestos a los jueces que consideraban opositores, reemplazándolos por jueces más favorables a sus propósitos. El primer presidente democrático electo luego del fin de la dictadura, Raúl Alfonsín, removió por tanto a una mayoría de estos jueces (incluidos los de la Corte Suprema), una vez llegado al poder, en 1983. Volvió a designar, en cambio, a los jueces considerados relativamente liberales y técnicamente competentes, por lo cual hubo una cierta continuidad entre ambos regímenes. Como parte de su política destinada a llevar a la justicia a los militares que hubieran violado derechos humanos, Alfonsín implementó una reforma del Código Militar, en $1984^{17}$. De todos modos, Alfonsín hizo poco en pos de un cambio en el sistema de justicia civil. Este cambio se produjo después, durante el gobierno del presidente Menem, que comenzara en julio de 1999, luego de que Alfonsín se viera obligado a dejar el poder seis meses antes del fin de su mandato. Las reformas, de todos modos, no se vincularon directamente con este cambio de gobierno.

17. Para detalles, ver RONIGER (1999: 59). 


\section{III.3. Esfuerzos en pos de la reforma judicial}

Reformas en la justicia penal

En el sistema de justicia penal, Argentina ha llevado adelante un largo y gradual proceso de reformas. La provincia de Córdoba adoptó los procedimientos orales hace ya mucho tiempo, en 1940. De hecho, ésta fue la primera vez que se introdujeron cambios en los procedimientos orales en toda Latinoamérica. El Código de Córdoba sirvió como modelo para el resto de Argentina, y se expandió así a las demás provincias entre los años 1940 y 1950. Las reformas más recientes en el sistema penal comenzaron formalmente en 1993, cuando Argentina adoptó un nuevo Código de Procedimiento Penal para su Tribunal Federal, que cambió los procedimientos escritos por orales. El nuevo procedimiento oral requiere también una mayor participación por parte de los jueces $^{18}$. El Código de Procedimiento Penal nuevo, adoptado en Argentina, ha servido como modelo en muchos otros países de la región.

Las reformas constitucionales de 1994

En agosto de 1994, Menem llevó adelante una profunda reforma constitucional, que afectó de modos diversos el aparato estatal. Las reformas directamente vinculadas con el poder judicial fueron cinco: 1) la creación de un Consejo de la Magistratura (art. 114); 2) la instalación de un Jurado de Enjuiciamiento; 3) la declaración del Ministerio Público como un órgano independiente (art. 120); 4) los cambios en los procedimientos de designación de los jueces de la Corte Suprema; y 5) las garantías constitucionales para los salarios de los miembros de la Corte Suprema y tribunales inferiores (art. 110) ${ }^{19}$.

Tal vez la reforma más importante sea la que implicó que muchas de las tareas administrativas realizadas por la Corte Suprema se hayan transferido al Consejo de la Magistratura. Dicho Consejo se encuentra compuesto por veinte miembros que representan al Congreso, al Poder Judicial, al Ejecutivo, tanto como a las asociaciones de abogados y a la Universidad. El Consejo cuenta hoy con amplios poderes, que incluyen una activa participación en la selección de los jueces federales (excepto los de la Corte Suprema, que siguen siendo nombrados por el procedimiento tradicional), la supervisión del presupuesto y los aspectos organizativos de los tribunales, tanto como funciones disciplinarias sobre los miembros del poder judicial ${ }^{20}$. El Centro de Estudios Legales y Sociales, CELS, ha considerado la creación del Consejo como una «absoluta necesidad», dado los múltiples problemas generados por la estructura

18. Para detalles, ver Cels (1995); ThOme (1998).

19. Los datos están tomados del texto de la Constitución argentina de 1994. Para detalles, ver CELS (1995: 79). El texto de los artículos y un comentario sobre los mismos en SABSAY (1998).

20. Thоме (1998: 16). 
judicial anterior ${ }^{21}$. Por ejemplo, en 1994, la Magistratura (que, antes de la reforma, se encargaba con exclusividad de la fiscalización de la disciplina judicial) tenía 350 casos que examinar en relación con faltas atribuidas a los magistrados ${ }^{22}$.

El Consejo debía estar en funcionamiento después de un año de su creación, pero el mismo no comenzó a operar hasta febrero de 1999. Una vez establecido, su labor resultó mucho más lenta de lo esperado. Esto ha creado una diversidad de problemas, incluidos algunos drámaticos vinculados con la necesidad de completar vacantes en posiciones judiciales $^{23}$. En agosto del 2000, el Consejo sólo llegó a completar dos nombramientos de jueces inferiores, de entre los más de 70 que debía realizar. De acuerdo con la opinión de uno de sus miembros, parte del problema se originó en un mandato pobremente definido, tanto como en la composición diversa del Consejo, que representa a intereses demasiado conflictivos entre $\mathrm{si}^{24}$. El Jurado de Enjuiciamiento, que se encuentra a cargo de la remoción de jueces nacionales, excepto los de la Corte Suprema nacional, ha tenido un destino similar al del Consejo. Dado que su trabajo se encuentra directamente ligado a éste, ha tenido un desempeño muy lento desde su creación.

En relación con otra de las reformas institucionales implementadas, vinculada con el artículo 120 de la nueva Constitución, encontramos que se ha definido al Ministerio Público como un órgano independiente, con autonomía funcional y autonomía financiera, pero que no se ha definido adecuadamente la posición de esta institución frente a las tres ramas de gobierno existentes. Esta situación ha llevado a algunos especialistas en Derecho constitucional a hablar de éste como un órgano extrajudicial. De acuerdo con el CELS, su autonomía funcional y financiera es polémica, tanto como lo es su autonomía frente al Ejecutivo ${ }^{25}$.

Finalmente, la reforma constitucional de 1994 cambió también los procedimientos de designación de los miembros de la Corte Suprema. Elevó la mayoría simple en el Senado, necesaria para aprobar el nombramiento de un juez, a la de dos tercios de los miembros presentes en el Senado ${ }^{26}$. Además, se garantiza ahora cierto salario mínimo para todos los jueces, asegurando así también la independencia financiera de todos ellos.

21. Cels (1995: iii).

22. DAKOlias (1996: 18, n. 18).

23. De acuerdo con la nueva ley, el nombramiento de los jueces inferiores sólo puede ser realizado por el Consejo. Por lo tanto, en el período que corrió desde el fin del sistema anterior (agosto de 1995) al comienzo del funcionamiento del nuevo instituto (febrero de 1999), no se pudieron realizar nombramientos de jueces inferiores.

24. Comunicación personal con Claudio Marcelo Kiper, Buenos Aires, 4 de agosto de 2000.

25. Cels (1995: 81).

26. Ibídem, pp. 80 . 


\section{III.4. Motivación de las reformas}

\section{Reformas al Código de Justicia Penal}

Si comparamos estas dos partes de la reforma, encontramos en realidad motivaciones y propósitos muy diferentes para cada una de ellas. En cuanto a la reforma del sistema de procedimiento penal, introducido en el nivel federal en 1993, la misma fue llevada a cabo por un grupo de académicos vinculados fundamentalmente con el teórico legal, el juez Julio Maier, y el Dr. Alberto Binder ${ }^{27}$. Resultaba obvio que debía realizarse algo en cuanto a la administración de justicia, luego de la vuelta a la democracia, en $1985^{28}$.

Las causas directas de la reforma fueron, al menos, tres. Primero, el fracaso del sistema judicial vigente durante el gobierno militar, un fracaso especialmente notable en el área de los derechos humanos. Los tribunales fueron severamente criticados por su actuación durante la dictadura, cuando más de 10.000 personas «desaparecieron» y miles más fueron encerrados en prisión, torturados y finalmente muertos. El gobierno, por lo tanto, necesitaba poner en marcha medidas que sirvieran para recuperar la legitimidad del sistema judicial. En segundo lugar, la cantidad de casos por resolver se había incrementado extraordinariamente, sobre todo a partir de demandas que se originaban tanto en razón de la democratización reciente como debido a la liberalización económica promovida por el gobierno de Menem, después de la crisis económica heredada del gobierno de Alfonsín ${ }^{29}$. Tal como ocurriera en otros países latinoamericanos, las reformas económicas crearon toda una nueva serie de problemas legales que debieron ser resueltos por los tribunales. En tercer lugar, y en relación con la crisis económica y el desempleo creciente, Argentina experimentó un dramático incremento en las tasas de criminalidad y violencia, lo cual puso una presión adicional sobre la justicia penal. La creciente preocupación en materia de seguridad pública ha sido citada de modo habitual como una motivación importante detrás de las reformas al sistema penal.

En suma, las motivaciones que han llevado a una refoma en el sistema de procemiento penal en Argentina son variadas, y vinculadas a una compleja red de factores, que incluyen el deseo del gobierno de reforzar la confianza en el sistema judicial y reducir ineficiencias propias del mismo, así como también su voluntad de atender las preocupaciones ciudadanas en relación con cuestiones sobre la seguridad y la violencia callejeras. La iniciativa en favor de las reformas vino desde la academia, pero el gobierno también dio, al menos, un respaldo parcial a las mismas. Los actores internacionales

27. Maier y Binder han sido considerados los «gurúes» de las reformas judiciales en América Latina, ya que no fueron sólo los principales cerebros detrás de las reformas implementadas en Argentina. Ambos viajaron extensamente por Latinoamérica, asesorando a una diversidad de gobiernos, entre ellos los de Venezuela, El Salvador y México.

28. Comunicación personal con Julio B. Maier, Buenos Aires, 4 de agosto del 2000.

29. Vicente Palermo ha sostenido que «uno podría decir que el gobierno, más que tomar la decisión de implementar las reformas, se vio literalmente empujado a adoptarlas a raíz de la fatal combinación de circunstancias que llevaron al colapso financiero del país» (PALERMO 1998: 144). 
parecen haber jugado un papel muy limitado en estas reformas. El Banco Interamericano de Desarrollo dio apoyo, desde 1997, a un amplio proyecto sobre las reformas judiciales, que tuvo entre otros objetivos el de reforzar el rol del procurador de la nación ${ }^{30}$. Según entiendo, otras agencias internacionales, tales como el Banco Mundial, USAID y la Fundación Ford, no han estado involucradas en la promoción de reformas en la justicia penal en Argentina ${ }^{31}$.

Reformas constitucionales que afectaron a la Corte Suprema

Las motivaciones que han estado detrás de las reformas estructurales de la Corte Suprema representan una historia completamente diferente. De hecho, la reforma constitucional de 1994 puede ser atribuida a un único factor causal decisivo: la voluntad del presidente Menem de ser reelegido como tal. De acuerdo con la Constitución de 1853, los presidentes sólo podían servir durante un mandato. Para volver a ser presidente, entonces, Menem debía reformar la Constitución. Por ello, comenzó un proceso de cuidadosas negociaciones con la oposición, destinadas a llevar adelante aquella reforma.

La mayoría de los académicos y expertos legales en Argentina están de acuerdo con que Menem negoció el apoyo legislativo a la reforma a cambio de un incremento en los poderes de la Corte. Carlos Santiago Nino ha sostenido, de modo convincente, que «bajo la presidencia de Menem... resulta claro que el eje central de la reforma constitucional es el logro de su reelección ${ }^{32}$. El CELs ha afirmado que la idea fue entonces la de asegurar que la oposición no obstaculizara los cambios constitucionales necesarios para conseguir la reelección del presidente. A cambio de ello, la oposición exigió una serie de reformas destinadas a crear o modificar instituciones que pudieran restringir los poderes del presidente, y asegurarle a la oposición un rol más activo en el gobierno, facilitándole además mayores herramientas de control sobre el mismo ${ }^{33}$. Tras largas y arduas negociaciones, el gobierno de Menem consiguió empujar estas reformas asegurando, entre otras cosas, un cambio en el término del mandato presidencial (que pasó de un período de seis a hasta dos períodos de cuatro años, según el artículo 90 de la Constitución). La reforma fue negociada por el Partido Peronista en el gobierno, junto con el principal partido de la oposición, el Radicalismo. Dicha negociación pasó a ser conocida con el nombre de «Pacto de Olivos» ${ }^{34}$.

30. Para detalles al respecto, ver Domingo (2001: 117).

31. Para una discusión acerca del involucramiento de las agencias internacionales en los distintos aspectos de la reforma judicial en Latinoamérica, ver BIEBESHEIMER (2001); DOMINGO (2001); FORD FOUNDATION (2002); WORLD BANK (2002).

32. NiNO (1992: 638).

33. CELS (1995: 75).

34. Ver FinKel (1999); Helmke (2002: 24). 
Es cierto que un tribunal más independiente -al menos teóricamente- podía beneficiar tanto a las nuevas cuestiones vinculadas con los cambios económicos como a las referidas a los derechos humanos. Sin embargo, la reforma constitucional de 1994 no puede ser atribuida fácilmente a factores económicos, dado que la Corte ampliada en número ya había dado su apoyo a las políticas económicas de Carlos Menem (ver detalles más abajo). Del mismo modo, no existía por entonces una presión evidente de parte de los organismos de derechos humanos, destinada a reformar la Corte. Las organizaciones no gubernamentales dedicadas a los derechos humanos ya habían manifestado sus críticas al modo en que eran tratados los casos de violaciones de derechos humanos, pero ninguna de ellas había realizado actividades en favor de la reforma judicial ${ }^{35}$.

En suma, podríamos concluir, de modo tentativo, que la reforma introducida sobre la Corte Suprema resultó un subproducto de la negociación llevada a cabo por Menem con la oposición, y que le permitió pelear por la Presidencia, nuevamente, y de modo exitoso, en las elecciones de 1995. Existieron, entonces, pocas intenciones nobles detrás de la reforma. El resultado, de todos modos, fue un incremento en la independencia judicial. Intuitivamente, uno no debería esperar que el presidente, de modo voluntario, aceptara ceder su control sobre el poder judicial. Sin embargo, Menem obviamente valoraba más la reelección que el mantener un control firme sobre la Corte. Dado que ya había aumentado el número de miembros de la misma, de cinco a nueve, después de obtener su victoria electoral frente a Alfonsín, Menem ya se había asegurado el apoyo de los jueces antes de realizar la reforma. El hecho de expandir los poderes del tribunal, luego, no debía ser necesariamente dramático. Uno podría argumentar, además, que la garantía constitucional de una mayor independencia judicial podía-hipotéticamente- beneficiar a Menem en caso de perder la Presidencia.

Los cambios en la composición de la Corte

Debe enfatizarse, a esta altura, la importancia que han tenido los cambios en la composición de la Corte, dentro de la historia jurídica argentina. Aunque la Constitución garantiza un mandato de por vida a los jueces de la Corte Suprema, ellos han sido habitualmente removidos de modo más o menos discrecional por las autoridades de turno. De hecho, la Corte Suprema argentina ha sido reemplazada de modo completo al menos seis veces desde $1946^{36}$. En septiembre de 1987, el gobierno de Alfonsín había comenzado a negociar con la oposición peronista el aumento en el número de miembros de la Corte de cinco a siete. Sin embargo, el intento terminó en un fracaso. Cuando Menem llegó al poder, en cambio, logró cambiar de un modo exitoso la composición

35. Esta afirmación resume la evidencia que he recogido a partir de una treintena de entrevistas realizadas a expertos legales (abogados, jueces, asistentes en la Corte), activistas de derechos humanos y periodistas ocupados en cuestiones judiciales. Las entrevistas fueron realizadas en Buenos Aires en el período julio-agosto del año 2000. Ver Apéndice 1 para más detalles.

36. OAS (1994). 
del tribunal, incrementando su número de cinco a nueve miembros. Aunque este aumento difícilmente se califique como una reforma legal, el mismo aseguró sin dudas el control de Menem sobre la Corte. Según la opinión de una diversidad de autores, Menem amplió la Corte con el objeto de impedir la oposición de la misma a las reformas económicas que trataba de implementar al comienzo de su mandato ${ }^{37}$. En definitiva, los esfuerzos destinados a cambiar la composición del tribunal durante los mandatos de Alfonsín y Menem parecen haber sido el resultado de estrechos intereses concernientes al uso y ejercicio del poder.

\section{CHILE}

\section{IV.1. Introducción}

A diferencia de lo ocurrido en el caso de Argentina, en donde la reforma en el procedimiento penal y la reforma de la Corte Suprema aparecieron como dos eventos separados entre sí, las reformas judiciales llevadas adelante en Chile se han desarrollado de un modo muy gradual, en un espacio prolongado de tiempo, conteniendo numerosas propuestas que incluyeron, también, modificaciones respecto de la Corte Suprema. Bajo el primer gobierno democrático, liderado por Patricio Alwyn (19901994), se realizaron numerosos y fracasados intentos de reforma judicial. Las propuestas eran entonces presentadas al Parlamento, que indefectiblemente las rechazaba, modificaba o reescribía, para presentarlas luego en una forma completamente diferente. Con el cambio de intereses y el ingreso de nuevos actores en la escena, los cambios resultaron más exitosos durante el gobierno de la Concertación liderado por Eduardo Frei (1994-2000). Las mismas continuaron exitosamente bajo el gobierno de la coalición socialista liderada por Fernando Lagos (del 2000-al presente) y no han alcanzado aún su etapa final de implementación.

En esta sección, pretendo dar cuenta de tres intentos fundamentales de reforma, realizados bajo tres gobiernos democráticos diferentes, especificando el contenido de cada una de estas reformas o propuestas, identificando a sus defensores y detractores, y ofreciendo algunas explicaciones en torno al porqué de las mismas. En donde ello sea necesario, comentaré también por qué muchas de las primeras propuestas de reformas resultaron un fracaso. La motivación para el primer paquete de reformas desplegado al comienzo de la transición democrática emanó de una fuerte inconformidad con el modo en que había estado operando el sistema judicial durante el período de la dictadura. Realizaré, por tanto, unos breves comentarios acerca del sistema judicial existente antes de la transición.

37. Ver, por ejemplo, FinKEL (1999); RONIGER (1997). 


\section{IV.2. El sistema judicial durante el gobierno militar y en el tiempo de la transición}

Chile es uno de los pocos países de América Latina cuyos tribunales permanecieron básicamente intactos desde la llegada al gobierno de las Fuerzas Armadas. La Corte Suprema, por entonces, se había mostrado claramente opuesta al así llamado experimento socialista llevado adelante por el gobierno de Salvador Allende. Esta oposición se vio reflejada, por ejemplo, en la resistencia de la Corte a apoyar algunas de las reformas económicas avanzadas por aquel gobierno. Hacia el final del gobierno de Allende, la Corte había denunciado de modo explícito al mismo ${ }^{38}$. Como era esperable, entonces, la conservadora Corte dio la bienvenida al nuevo gobierno militar que derrocó al de Allende, en un golpe producido en 1973. Dada la falta de oposición o protesta por parte del poder judicial, los militares no encontraron razones para interferir en el sistema judicial. De hecho, la justicia chilena -tradicionalmente conservadora- fue utilizada como un testigo legal, por parte de la dictadura, para demostrar que era respetuosa con las instituciones democráticas.

La trayectoria de la justicia chilena durante esos años dista de ser impecable. En aquella época, existía una represión generalizada, miles de personas fueron asesinadas o desaparecidas. De acuerdo con Robert G. Vaughn, «durante el régimen militar, el poder judicial, y en particular la Corte Suprema, no protegió de modo adecuado a las personas que buscaban reparación. El poder judicial apareció condonando los abusos realizados por los militares y creó dudas sobre la posibilidad de resguardar los derechos y libertades personales a través del medio judicial» ${ }^{39}$. Como regla general, entonces, se tendió a ignorar cada una de las peticiones de hábeas corpus presentados, salvo en unas pocas excepciones. Los jueces inferiores que no acataban las decisiones de sus superiores corrían el riesgo de caer en problemas. Aunque muchos de los miembros de la Corte eran abiertamente simpatizantes del gobierno militar, Pinochet poco a poco endureció sus controles sobre el tribunal. Durante sus 18 años de mandato, Pinochet nombró a 14 de los 17 jueces superiores. Doce de ellos fueron nombrados entre 1985 y $1989^{40}$. Con el objeto de asegurar su futura influencia sobre la Corte, después de perder inesperadamente el plebiscito de 1989, Pinochet aumentó el número de miembros de la Corte de 13 a 17 miembros, antes de dejar el poder. De modo adicional, ofreció altas sumas de dinero para aquellos que se retiraran voluntariamente. Dado que la Constitución de Chile, como la de Argentina, garantiza estabilidad de por vida a los jueces (una regla que, a diferencia de lo ocurrido en la Argentina, siempre se respetó en Chile), Pinochet conseguía de ese modo preservar su influencia sobre la vida política chilena tras dejar el poder. Dado el carácter jerárquico del sistema judicial chileno y el grado de control ejercido por la Corte Suprema sobre los tribunales inferiores, Pinochet se aseguró que los militares tendrían una protección especial durante la nueva democracia. Su principal preocupación, por supuesto, era la de asegurarse protección en materias vinculadas a la violación de derechos humanos.

38. Detalles al respecto en Vaughn (1992: 583).

39. Ibídem, p. 583.

40. Ibídem, p. 583, n. 46. 


\section{IV.3. Esfuerzos en favor de la reforma}

Primeros intentos. Las «Leyes Cumplido»

Cuando Patricio Alwyn se hizo cargo del poder en marzo de 1990, heredó un sistema judicial que carecía de respeto y prestigio, encabezado por una Corte Suprema compuesta por una mayoría de jueces favorable a Pinochet ${ }^{41}$. De modo adicional a la Corte, claramente no democrática, Alwyn heredó también un anticuado sistema de justicia penal. El sistema y sus procedimientos no habían sido alterados desde 1906, y se caracterizaba por atributos premodernos que databan de los tiempos de la colonia ${ }^{42}$.

Por lo tanto, como era de esperar, el primer gobierno democrático electo en 1989 tras 18 años de gobierno dictatorial, tuvo a la reforma judicial entre sus principales prioridades $^{43}$. El presidente Patricio Alwyn tenía fuertes deseos de realizar una reforma que asegurara un poder judicial más transparente y eficiente, y también de remover a los integrantes de la Corte Suprema. Su propósito era doble: modernizar la justicia dejando atrás el anticuado sistema judicial y el arcaico Código Penal, y también asegurar una mayor protección en el futuro para los derechos humanos.

Un grupo de expertos legales, miembros del gobierno, y defensores de la Corte Suprema, comenzaron a estudiar entonces una diversidad de reformas. Las propuestas fueron desde las más técnicas y procedimentales a aquellas otras destinadas a cambiar la estructura general del sistema. Las reformas incluyeron sugerencias para crear un Consejo de la Magistratura (como el que existía en Italia o en España); establecer tribuanales vecinales para contribuir a solucionar problemas propios de los ciudadanos con menores recursos; modificar los procedimientos (incluyendo, por caso, cambios en la forma de acceso a la Corte; un menor apoyo en la evidencia escrita; procedimientos informales para la resolución de algunos casos); cambiar la naturaleza de la carrera judicial; alterar los criterios evaluativos y los procedimientos para llegar al cargo de juez; tomar en cuenta el rol de los «fiscales integrados»; estableciendo una edad máxima para ejercer como juez; creando una Escuela Judicial; aumentando el número de miembros de la Corte Suprema y dividiéndola en salas especializadas; reformando la concepción dominante sobre el sistema de separación de poderes; e incorporando moderna tecnología y otras técnicas destinadas a la administración de los tribunales ${ }^{44}$.

41. Pinochet permaneció entonces como jefe de las Fuerzas Armadas, dejando así a los militares con importantes enclaves de control, directo e indirecto, sobre la nueva democracia.

42. Por detalles al respecto, ver BICKFORD (1998: 15).

43. Adviértase que los esfuerzos realizados al respecto no eran nuevos. El sistema penal chileno, basado en la Inquisición española, sufrió varios intentos de reforma. Se realizaron enmiendas a la Constitución en los años 1810, 1812, 1818, 1823, 1828 y 1833. Los orígenes del actual Código Penal chileno se encuentran en las leyes sancionadas en 1884, 1906 y 1970. Reformas judiciales más extensas aparecieron, como propuestas, durante el gobierno de Allende en 1970, pero la Corte bloqueó estos intentos de reforma encabezados por la Unidad Popular (BICKFORD, 1998).

44. Esta lista (parcialmente modificada) está tomada de VAUGHN (1992: 589-590). 
Después de un intenso debate en torno a las reformas, el nuevo gobierno presentó al Congreso un paquete más reducido de propuestas, en 1991. El paquete incluía, por ejemplo, el establecimiento de un Consejo de Magistratura, y un incremento en el número de jueces de la Corte. Al nivel de la administración de justicia, se propusieron reformas que tendían a cambiar por completo el sistema de procedimiento penal ${ }^{45}$.

El paquete de reformas, conocido como «Leyes Cumplido» (a partir del nombre del ministro de Justicia, Francisco Cumplido, su impulsor) encontró dos frentes de oposición muy importantes. En primer lugar, la Corte Suprema se opuso a todas las refomas que afectaban su poder, en particular aquellas que se vinculaban con la creación de un Consejo de la Magistratura. Sus miembros sostenían que las mismas iban a reducir considerablemente sus funciones, y aun su autoridad sobre los tribunales inferiores $^{46}$. Dado que estos cambios iban a requerir modificaciones en las leyes orgánicas, la Corte Suprema iba a poder controlar algunos de estos cambios, en caso de ser impulsados por el Congreso. Por lo demás, los legisladores más conservadores (notablemente, los «senadores designados») pudieron bloquear el paso de la reforma por el Senado, en 1991. Por ello, este primer intento de reformas terminó con un fracaso.

Segundo intento de reformas. Las «Leyes Alwyn»

Un segundo intento de modernizar el sistema judicial durante el nuevo período democrático apareció con el gobierno de Alwyn, y a través de las llamadas «Leyes Alwyn», dirigidas fundamentalmente a cambiar la estructura del poder judicial alterando los procedimientos de designación de los jueces de la Corte Suprema y creando dos nuevos institutos (una oficina de Defensoría Pública, y un ombudsman). Las «Leyes Alwyn» incluían también el establecimiento de una Academia Judicial; la creación de un servicio nacional de asistencia judicial (destinado a proveer un acceso más igualitario a la justicia para los sectores más pobres); y el establecimiento de los fiscales de ofi$\mathrm{cio}^{47}$. El ministro de Justicia introdujo estas reformas en el Parlamento en abril de 1991. Sin embargo, también este intento estaba destinado a fracasar. La Corte Suprema se opuso rotundamente a la misma y el Congreso defendió la postura de la Corte y rechazó la petición del presidente. De allí que, durante la administración Alwyn, fue poco lo que se hizo en términos de reforma judicial, sobre todo debido a la oposición proveniente de la Corte Suprema y el bloque conservador (que incluía a los senadores de por vida incluidos por Pinochet) en el Senado chileno.

45. Una descripción abarcativa de este paquete de reformas en BICKFORD (1998: 25, n. 21).

46. De acuerdo con una entrevista con Jorge Mera, Santiago, 16 de mayo del 2000. Ver también VAUGHN (1992: 589, n. 61).

47. Ver BICKFORD (1998: 25, n. 21). 
El tercer intento de reformas

La exitosa Concertación presidida por el presidente Eduardo Frei hijo, con la guía de su ministra de Justicia Soledad Alvear, avanzó con una estrategia diferente. En lugar de proponer amplios paquetes de reforma, comenzó a introducir reformas minúsculas, tratando de crear consenso poco a poco y calculando el tiempo de introducción de las mismas avanzando, en primer lugar, aquellas reformas menos controvertidas ${ }^{48}$. Después de cuidadosas negociaciones las reformas comenzaron a tomar vuelo y se aprobaron al menos dos leyes muy significativas en 1997: una reforma de la justicia penal y una ley de reforma de la Corte Suprema.

En primer lugar, se propusieron a la legislatura normas destinadas a crear un nuevo Código de Procedimiento Penal y otras normas complementarias. El elemento más importante, dentro de estas reformas, era -posiblemente- el vinculado a la creación de un sistema adversarial, que dejaba de lado la tarea de los jueces como acusadores. De modo más específico, la reforma incluía los siguientes elementos ${ }^{49}$ :

1. Abolición del sistema de investigación judicial (la institución inquisitorial hasta entonces vigente), y reemplazo del mismo por un sistema basado en un Ministerio Público. El nuevo Ministerio Público se encontraría a cargo de la persecución de los crímenes $^{50}$.

2. La introducción de juicios orales, que incluirían la posibilidad de examinar a los testigos a partir de un sistema especial, consistente en paneles de tres jueces, que venían a reemplazar a los tradicionales -medievales- y muy criticados procedimientos en los que un único juez actuaba como investigador y juez.

3. Introducción de una reforma destinada a favorecer la negociación entre el fiscal y el defensor, así como de una lista de derechos para el defensor (nótese que la mayoría de estos cargos no existían en el sistema anterior).

4. Reorganización de los tribunales, incluyendo la eliminación de los secretarios de Corte, y el nombramiento de un administrador profesional del tribunal.

5. Reorganización y extensión de la oficina de Defensoría Pública, destinada a tornar a la justicia más accesible para los grupos de pobres y marginados.

6. Finalmente, reformas procedimentales destinadas a crear una Academia Judicial, finalmente aprobada a través de la Ley $19.346^{51}$.

48. Ibídem.

49. La lista es tomada de Thome (1998: 17-18).

50. Para detalles sobre esta reforma en el procedimiento penal, incluyendo la labor del Ministerio Público, ver De La BARRA (1999); DuCE (1999); RIEGO (1997).

51. Antes del establecimiento de la Academia Judicial, la entrada al poder judicial se vinculaba con un procedimiento cerrado, en donde el presidente seleccionaba al candidato de una lista de tres nombres preparada por la Corte Suprema o las Cortes de Apelación. El nuevo sistema intentaba remover los aspectos personales y discrecionales vinculados con el procedimiento anterior, para reemplazarlo por otro basado en el mérito. La Academia ofrece, también, un sistema de educación legal continua destinado a los jueces en funciones, y se propone atraer a los mejores candidatos para ingresar dentro del sistema judicial (ThOme, 1998: 17). 
En su conjunto, estas reformas constituyeron, posiblemente «la reforma estructural más importante en toda la historia de la administración de la justicia chilena $\gg^{52}$. Para propósitos prácticos, se decidió que las reformas serían implementadas gradualmente, y no en todas las regiones a la vez. Las primeras reformas se introdujeron en La Serena y en otra región. Santiago -la capital- sería la última región en implementar estas reformas. Se espera que el proceso de implementación culmine a fines de 2003.

El presidente Frei también propuso reformas para mediados de julio de 1997, reformas que incluían cambios en la composición de la Corte, y cambios en las reglas de designación de sus miembros, un aumento en el número de sus miembros, y una regla de retiro obligatorio para la edad de $75^{53}$. Un elemento central en estos nuevos procedimientos de designación era la regla de que, para poder ser nombrado juez, era necesaria la aprobación previa por $2 / 3$ del Senado. Esto significa que el Ejecutivo ha perdido parte de su poder de control sobre la nominación de los jueces.

Finalmente, el Congreso adoptó la Ley de Reformas de la Corte Suprema en $1997^{54}$. Este resultado fue, de algún modo, sorpresivo, dado que al menos ocho de los 17 miembros de la Corte eran -según se sabía- opuestos a todas las reformas que pudieran implicar una simplificación en los procedimientos judiciales, y aún más adversos a aquellos cambios en las reglas de selección de jueces ${ }^{55}$. ¿Cuáles fueron las motivaciones detrás de estos varios intentos de reforma? Y ¿por qué las reformas finalmente resultaron exitosas durante el gobierno de Frei, después de tantos intentos fallidos bajo la administración de Alwyn?

\section{IV.4. Por qué las reformas}

Primeros intentos de reforma

Cada una de las reformas discutidas más arriba tenían, detrás de sí, su particular constelación de defensores y enemigos, cada uno con sus peculiares intereses. El primer intento amplio por establecer reformas en la administración judicial, durante la primera etapa de la transición, apareció indudablemente motivado por los fracasos del sistema judicial en el período de la dictadura - especialmente la incapacidad de las Cortes de defender los derechos humanos y proteger las libertades de los individuos ${ }^{56}$. El mismo presidente, Patricio Alwyn, y su equipo de apoyo en el Ministerio de Justicia, jugaron un rol central en este proceso. El experto legal Juan Enrique Vargas sugiere que el impulso en favor de estas primeras reformas provenía del intento del gobierno por dejar

52. De la BARRA (1997: 18).

53. Southern Cone Report RS-97-06 (29 de julio de 1996: 2).

54. BICKFORD (1998).

55. Southern Cone Report RS-97-05 (24 de junio de 1997: 7).

56. Adviértase que ha habido un fuerte apoyo a las reformas en los 70 y en los 80 , especialmente a partir del trabajo del Grupo 24, pero los mismos no resultaron exitosos: las reformas no fueron aprobadas por la dictadura. Comunicación personal con Jorge Correa Sutil, Santiago, 15 de mayo de 2000. 
atrás el legado de Pinochet, tanto como de su empeño por revertir la poca legitimidad de la justicia, además de ampliar su capacidad para lidiar con temas de derechos huma$\operatorname{nos}^{57}$. Del mismo modo, Jorge Correa Sutil sostiene que las críticas dirigidas hacia el poder judicial por el desempeño que había tenido durante el gobierno de Pinochet jugaron un «rol crítico» en los intentos del gobierno de la Concertación por avanzar estas reformas $^{58}$. De acuerdo con el juez Mario Garrido Montt, la crisis producida por la negativa de la Corte a lidiar con cuestiones de derechos humanos resultó «explosiva» a la hora de dar impulso a estas reformas ${ }^{59}$. De hecho, muchos han sostenido que este primer intento de reformas fue motivado principalmente por los abusos producidos en el área de los derechos humanos, aunque no todos están de acuerdo con esta afirmación ${ }^{60}$.

\section{Reforma en la justicia penal}

Contra lo ocurrido con los dos primeros intentos de reforma, el tercero no fue solicitado por el gobierno de Frei. La reforma en la justicia penal resultó el producto de una iniciativa académica presentada por teóricos que trabajan en la Universidad Diego Portales en cooperación con otras instituciones. Parece, además, que la prensa ha jugado un rol importante en todo este proceso, al crear presión sobre el gobierno, en favor de estas reformas. El impulso reformista -ya sea que las reformas finales fueran exitosas o no- ha hecho que el gobierno ganara aprobación tanto interna como externa, desde la comunidad internacional ${ }^{61}$. Parte del incentivo para la realización de las reformas, sin duda, provino del deseo de alentar las inversiones de compañías extranjeras, un objetivo importante para el gobierno chileno, que ha impulsado un modelo de liberalización económica desde los 90. Este objetivo aparece claramente explicitado en la propuesta de reforma ${ }^{62}$. De acuerdo con el académico Jorge Mera, «el impulso por la reforma ha provenido del deseo de modernizar al Estado». Más aún, en su opinión «las reformas fueron realizadas con el objeto de crear más seguridad a las inversiones de capital, fundamentalmente a las inversiones extranjeras» ${ }^{33}$.

57. Comunicación personal con Juan Enrique Vargas, Santiago, 11 de mayo de 2000.

58. Comunicación personal con Jorge Correa Sutil.

59. Comunicación personal con Mario Garrido Montt, Universidad Diego Portales, Santiago, 29 de mayo de 2000.

60. Por ejemplo, de acuerdo con Louis N. Bickford, «el primer intento de reforma judicial por un gobierno democrático... resultó un pequeño esfuerzo dirigido a obtener otro fin, menor... la liberación de los prisioneros políticos encarcelados por su oposición al régimen militar» (BICKFORD, 1998: 24).

61. Comunicación personal con Juan Enrique Vargas.

62. Comunicación personal con Rodrigo de la Barra, Santiago, 13 de junio de 2000.

63. Comunicación personal con Jorge Mera. 
Otro factor importante fue la creciente preocupación con cuestiones vinculadas con la seguridad pública ${ }^{64}$. De modo más específico, existió un incidente particular que disparó esta preocupación por la seguridad. El asesinato del hijo del dueño del diario $E l$ Mercurio -un periódico de derechas, de alcance nacional-, Agustín Edwards, en 1992, hizo que la cuestión de la seguridad pública quedara instalada en la agenda política y llevó a la creación de la Fundación Paz Ciudadana. Esta organización no gubernamental comenzó a involucrarse de modo activo con los procedimientos de reforma penal. Su creación se debió, en parte, al financiamiento de la Fundación Ford. Dada su composición y sus vínculos explícitos con la comunidad de negocios y la derecha chilena, la Fundación terminó actuando como un puente entre la izquierda y la derecha, y aseguró el consenso necesario de la derecha para aprobar la ley respectiva, en 1997. La Corte Suprema se mantuvo dividida sobre la cuestión, pero terminó aceptando la reforma por una mayoría de un voto, antes de que su número se aumentase a 21 jueces ${ }^{65}$. La implementación de la reforma comenzó en agosto de 2000. Se espera que la misma se complete hacia el 2003.

\section{Reforma en la Corte Suprema}

Aunque la reforma de la Corte Suprema forma parte de un paquete de reformas más amplio, la principal motivación detrás de este cambio resultó diferente de la que impulsó las modificaciones en el procedimiento penal. Contra lo ocurrido en relación con la Ley de Procedimiento Penal -que fue el producto de un largo proceso de negociaciones y compromisos, y que necesitó también de una amplia asistencia técnica y financiera- los cambios relacionados con la Corte Suprema se realizaron en el lapso de un mes y medio ${ }^{66}$. La iniciativa directa provino de la ministra de Justicia Soledad Alvear, como respuesta a un escándalo de corrupción que involucró a la Corte Suprema. Brevemente, la ministra quiso remover al presidente del máximo tribunal (esto es, no «echarlo» pero sí llevarlo a la renuncia de su posición), debido a la aparente participación del juez en un escándalo relacionado con el tráfico de drogas ${ }^{67}$.

Una segunda razón que llevó a impulsar la remoción del presidente de la Corte fue que el mismo había adoptado una posición favorable a las causas de derechos humanos, y la derecha temía la persecución del personal militar por causas de ese tipo. Por su parte, la izquierda demandaba cambios en la composición de la Corte con el

64. Ver, por ejemplo, DE LA BARRA (1997); FRÜHLING E. (1998).

65. Comunicación personal con Jorge Mera.

66. Información proveniente de diversos teóricos del Derecho entrevistados en Santiago durante el período mayo-julio de 2000.

67. De acuerdo con la opinión de un académico (que pidió no ser nombrado), Alvear promovió la reforma con el único objeto de ganar popularidad, algo que por cierto obtuvo, ya que a ella se le adjudica el crédito por la reforma de la Corte. Este hecho pudo haber determinado la participación de Alvear como la primera mujer en convertirse en ministra de Relaciones Exteriores en Chile, bajo el gobierno de la Concertación, en el 2000. 


\section{UN ANÁLISIS DE LAS REFORMAS JUDICIALES DE ARGENTINA, CHILE Y URUGUAY}

objeto de aumentar el número de jueces, invitando a tales efectos a jueces ajenos a la carrera judicial tradicional. La izquierda pretendía, además, imponer un tope de edad de 75 años en los jueces. La derecha demandó entonces involucrar al Senado en los procesos de designación judicial. Tras intensas negociaciones, la ministra de Justicia pudo obtener un apoyo suficiente para conseguir que la reforma fuera aprobada en ambas Cámaras. Parece, en cambio, que la reforma no estuvo motivada por preocupaciones económicas. Dado que Chile formaba parte ya del mercado de comercio internacional desde hacía por lo menos una década, y dado que la Corte había mostrado su apoyo a la política económica implementada por los gobiernos de Alwyn y Frei, la hipótesis de que las reformas tuvieron alguna vinculación con los intentos de liberalizar la economía no se sostiene. Tampoco parece que la misma haya tenido que ver con presiones provenientes de los sectores vinculados a los derechos humanos ${ }^{68}$. Aunque ambos sectores podían beneficiarse con la reforma, orientada a lograr un tribunal más independiente, lo cierto es que ellos no jugaron un rol significativo en la promoción de la misma.

\section{URUGUAY}

\section{V.1.Introducción}

A diferencia de lo ocurrido en Chile y Argentina, Uruguay aparece como el «perdedor» dentro de un contexto de promoción de reformas judiciales. En este caso no se produjeron reformas de importancia sobre el antiguo Código de Procedimiento Penal que todavía rige en el país. Tampoco la Corte Suprema sufrió reforma alguna desde el comienzo de la transición democrática, en 1985. Han habido, sí, debates en torno a reformas, pero éstas no han conseguido el apoyo suficiente como para llevarse a cabo. Tal vez de modo sorprendente, Uruguay ha tenido un rol de liderazgo en lo que se refiere a la reforma del Código de Procedimiento Civil.

En esta sección, se explica por qué Uruguay apareció jugando este rol opaco en Latinoamérica, en lo relativo a la reforma judicial. Existen al menos dos explicaciones plausibles para dar cuenta de por qué la justicia penal y la Corte Suprema no fueron objeto de reformas: 1) las mismas no eran necesarias dado que el sistema operaba de modo relativamente eficiente y la justicia era independiente, y 2) las reformas eran necesarias pero los factores causales que podían haber ayudado a promoverlas (la liberalización económica, las preocupaciones con cuestiones vinculadas con derechos humanos, la inseguridad, etc.) no estaban presentes. Antes de discutir las motivaciones existentes detrás de los procesos de reformas impulsados durante el período, es necesario hacer un repaso de la situación en el sistema judicial uruguayo en el período de

68. Esto es lo que se deriva de las entrevistas que he realizado a más de 30 especialistas en cuestiones legales, académicos, abogados de derechos humanos y activistas de derechos humanos, en el período mayo-julio de 2000, en Santiago. Para más detalles, ver Apéndice 1. 
la transición, de modo tal que se analice si las reformas podían considerarse realmente necesarias.

\section{V.2. El sistema judicial durante el gobierno militar y el tiempo de la transición ${ }^{69}$}

Los jueces uruguayos nunca fueron considerados cómplices de la dictadura (19761985), tal como sí había ocurrido en Chile y en Argentina. El poder judicial resultó marginado durante el gobierno militar. La Junta que tomó el poder tras el golpe del 76 realizó entonces varios cambios en el sistema judicial, incluyendo dos reformas institucionales a través de los artículos 8, de 1977, y 11, de 1981. Aunque los militares dejaron a la Corte en buena medida intacta, removieron a un buen número de jueces inferiores, a los que reemplazaron por otros que, asumían, iban a respaldarlos en sus decisiones. Los jueces de la Corte permanecieron en sus cargos, mientras que los militares iban completando las vacantes naturales que se producían, ya que la Asamblea General (a cargo del nombramiento de los jueces, durante la democracia) no estaba en funciones. La Corte siguió operando entonces de modo más o menos idéntico a lo que lo hacía antes del golpe militar. De todos modos, el gobierno militar creó dos nuevas instituciones administrativas destinadas a quitar a la Corte parte de sus poderes: el Ministerio de Justicia y el Consejo de la Magistratura.

Después del retorno de la democracia, en 1985, Julio María Sanguinetti, el nuevo presidente, reconoció a las autoridades judiciales existentes. La Ley Orgánica de la Judicatura (n. 15.750) volvió a entrar en funciones en 1985. Por su parte, el presidente abolió el Ministerio de Justicia y colocó al poder judicial bajo la órbita administrativa del Ministerio de Educación y Cultura, en donde permaneció hasta hoy. El gobierno, por otra parte, abolió el Consejo de la Magistratura. Aunque la institución resultaba útil, se consideró a la misma un resultado de la dictadura, que no merecía permanecer en pie en la nueva etapa democrática. Al mismo tiempo, se consideraron necesarias nuevas reformas en el sistema judicial, por entonces reconocido como lento e ineficiente. El acceso a la justicia era limitado, aún cuando Uruguay se destacaba por ser el tercer país con más jueces per cápita en el mundo. Este estado de cosas llevó a que se realizaran intentos de reforma en tres áreas diferentes (el Código de Procedimiento Civil, el Código de Procedimiento Penal y la Corte Suprema), de las cuales nos ocuparemos a continuación, con algún detalle.

69. Comunicación personal con Alberto Pérez Pérez y Fernando Urioste, Montevideo, 2 y 4 de abril de 2001, respectivamente. 


\section{V.3.Esfuerzos en pos de la reforma}

\section{Reformas en el Código de Procedimiento Civil ${ }^{70}$}

Después de casi catorce años de debate, Uruguay dictó un nuevo Código de Procedimiento Civil en $1989^{71}$, lo cual se consideró «un avance importante en materia de Derecho civil» ${ }^{72}$. El Código Civil abandonado databa de 1879, y era una copia del Código español de 1850, que contenía muchos elementos de origen medieval. De tal modo, la reforma resultó un intento de modernizar el sistema legal uruguayo. El académico Dr. Adolfo Gelsi Bidart había sugerido la reforma de la justicia civil ya en los años 40 , pero todavía tuvieron que pasar muchas décadas hasta que la reforma pudo concretarse, finalmente. El vicepresidente y procesalista Dr. Caligo volvió a poner la cuestión de la reforma en la agenda pública, una vez concluido el régimen militar, en 1985. Tres procesalistas, los doctores Gelsi, Bescovi y Torello, fueron convocados entonces para redactar el nuevo código. Se iniciaron entonces fuertes discusiones, dado que no todos estaban de acuerdo en la necesidad de introducir procedimientos orales. De todos modos, se llegó finalmente a un acuerdo en $1989^{73}$.

Con la reforma, se introdujeron tres nuevos procedimientos orales dentro del proceso litigioso anterior, basado en la evidencia escrita. Estos nuevos procedimientos incluyeron: i) una audiencia previa al juicio (destinada a alentar una conciliación entre las partes); ii) la presentación de la prueba (que incluía el interrogatorio a los testigos y una breve presentación de argumentos por cada una de las partes); y iii) la etapa de la sentencia. De acuerdo con el académico Joseph R. Thome, el nuevo sistema contaba con muchas ventajas. En la etapa preliminar, se podía llegar a precisar en detalle la cuestión bajo examen, aun cuando no se llegara a un acuerdo sobre la misma. Además, dicha etapa permitía a cada juez realizar una revisión del proceso e instruir a las partes acerca de cualquier deficiencia en sus presentaciones, en la prueba ofrecida, o en los costos involucrados. Posibilitaba, además, simplificar las etapas posteriores. Las audiencias orales permitían que las partes entendieran mejor el proceso legal. Y, tal vez lo más importante, se daba al juez un rol más significativo. Se reducía, entonces, el rol de los actuarios.

Otras medidas complementarias vinieron a acompañar a estas reformas. Entre ellas, el establecimiento de una Escuela Judicial, una expansión del poder judicial, un nuevo proceso destinado a la selección de jueces, y una reorganización administrativa del

70. Quiero agradecer a Joseph Thome por dejarme utilizar su trabajo en esta sección de mi escrito. Ver ThOme (1998). Según entiendo, éste es el único trabajo que existe en inglés acerca de la reforma al sistema de procedimiento civil en Uruguay. El excelente análisis de Thome fue acompañado por una serie de entrevistas que realizara con jueces y expertos legales en Montevideo, durante el período marzo-abril de 2001.

71. Código general del proceso en materia civil, Ley n. 15.982, aprobada el 18 de octubre de 1988, implementada en 1989, n. 16.053.

72. Comunicación personal con Jorge A. Marabotto, Montevideo, 28 de marzo de 2001.

73. Ibídem. 
sistema judicial. La nueva escuela judicial y centro de entrenamiento de los jueces (el Centro de Estudios Jurídicos del Uruguay, CEJU), fue inaugurado en 1990, y desde entonces cumplió un rol central en el proceso reformista. Los programas de entrenamiento judicial se consideran ahora casi obligatorios para comenzar una carrera, y los estándares de admisión se han convertido en más rigurosos. Esto, a su vez, ha mejorado la competencia formal de los jueces ${ }^{74}$.

A pesar de las debilidades que también ha mostrado, en líneas generales puede considerarse que la reforma civil uruguaya resultó un éxito. El código fue el primero de este tipo en Latinoamérica, y ha sido utilizado como modelo en muchos países, entre ellos Colombia y Bolivia ${ }^{75}$. A pesar de su condición de pionero en relación con el Código Civil, Uruguay no llegó a poner en marcha una reforma a su Código de Procedimiento Penal. Ello, no sólo por el hecho de que en Uruguay -y tal como lo señalara el Dr. Urioste- los cambios tiendan a ser «desesperantemente lentos» ${ }^{76}$.

Reformas en el procedimiento penal ${ }^{77}$

El Código de Procedimiento Penal en Uruguay fue adoptado por los militares en $1980^{78}$. Los debates sobre la reforma comenzaron poco después de que se iniciara la transición democrática, y de modo paralelo con las discusiones sobre las reformas en el procedimiento civil. Tras décadas de debate, se llevó a cabo un intento infructuoso de reforma en 1998. El mismo fue el producto de dos iniciativas independientes la una de la otra. El debate central se centró entonces en los procedimientos de justicia penal.

La primera iniciativa de reforma fue adelantada por el Instituto de Derecho Procesal Penal, en conjunción con la Corte Suprema, representada por el presidente de la Corte, Dr. Jorge Marabotto y los jueces Dr. Cairoli y Dr. Torello. La iniciativa fue apoyada, además, por numerosos académicos, que pensaron que era necesario llevar adelante reformas sustantivas. El grupo propuso introducir un sistema acusatorio, dar más poder al fiscal, y recortar las responsabilidades administrativas de los jueces, para permitirles una mayor atención de las tareas propiamente judiciales.

La segunda iniciativa de reforma provino del fiscal general Peri Valdez, y vino a favorecer la adopción de un sistema mixto, en donde los jueces retenían sus poderes inquisitoriales. Muchos jueces se mostraron entonces escépticos frente a la propuesta, dado su temor de que se incrementaran los poderes de los fiscales, comprometiendo

74. Una explicación más detallada de la reforma, de sus fortalezas y debilidades, en THOME (1998).

75. Comunicación personal con María del Carmen Rueco, Montevideo, 3 de abril de 2001.

76. Comunicación personal con Fernando Urioste, Montevideo, 4 de abril de 2001.

77. Gracias a Fernando Urioste, por facilitarme el conocimiento de tantos detalles acerca de las reformas al procedimiento penal en Uruguay. Urioste tuvo una participación activa en tales movimientos de reforma, en los años 1997-1998.

78. Código de Procedimiento Penal, Decreto Ley 15.032, del 7 de julio de 1980. 
de ese modo las facultades y la propia independencia de los jueces ${ }^{79}$. A pesar de esta divisoria inicial entre los jueces, Marabotto -quien defendió la primera de las iniciativas- considera que finalmente se produjo un cambio en la cultura política de los jueces, que han comenzado a apoyar de modo generalizado las reformas en favor de un proceso acusatorio ${ }^{80}$.

Tras largos debates, se presentó finalmente al Congreso un proyecto de reforma, en 1998. En síntesis, el mismo sugería la introducción de procedimientos orales para los casos penales, destinados a reemplazar la tradición española de los juicios escritos. De modo similar a lo ocurrido con el Código Civil reformado, se pretendía introducir un sistema de audiencias en la etapa preliminar del proceso, y en el plenario o etapa final del mismo ${ }^{81}$. La reforma propuesta tendía a darle al fiscal mayores poderes para investigar, aliviando así en parte las tareas que el antiguo sistema le asignaba a los jueces). El Congreso trató la iniciativa en 1998, pero la misma quedó estancada ${ }^{82}$. El Dr. Gonzalo Fernández realizó algunas correcciones al proyecto de reforma, pero la Asamblea General no se mostró interesada en el mismo. El nuevo código nunca pudo implementarse.

Muchos académicos uruguayos consideran que la cuestión de la reforma del Código de Justicia Penal se encuentra en una vía muerta. La Dra. Jacinta Balbela, por caso, considera que la cuestión no volverá a plantearse ${ }^{83}$. Del mismo modo, el especialista legal Dr. Pérez Pérez considera que dicha ley no va a ser implementada ${ }^{84}$. El especialista en Derecho procesal penal Dr. Urioste, es algo más optimista. En su opinión, en los próximos diez años podría llegar a presentarse la iniciativa de reforma, nuevamente, aunque no hay signos de que ello vaya a producirse en lo inmediato ${ }^{85}$.

En la próxima sección se analizan las causas de la reforma. Además, se intenta dar una respuesta tentativa al porqué del estancamiento de la reforma penal, frente a la aprobación de la reforma en el procedimiento civil.

\section{V.4.Motivación para las reformas. Sus éxitos y sus fracasos}

\section{Reforma en el Código de Procedimiento Civil}

El Código de Procedimiento Civil fue reformado, fundamentalmente, con el objeto de modernizar un código anticuado, mejorar el acceso del público a los tribunales

79. Comunicación personal con Jorge A. Marabotto.

80. Ibídem.

81. Los detalles sobre la propuesta me fueron suministrados por Jorge P. Pereira Schurmann, Montevideo, 4 de abril de 2001.

82. La Ley 16.893 adoptada el 16 de diciembre de 1997, modificó parte de la ley original introducida por los militares en 1980.

83. Comunicación personal con Jacinta Balbela, Montevideo, 6 de abril de 2001.

84. Comunicación personal con Alberto Pérez Pérez.

85. Comunicación personal con Fernando Urioste. 
civiles, y dotar a los tribunales de una mayor eficiencia. Las preocupaciones económicas no jugaron ningún rol en estas reformas, como tampoco lo hicieron cuestiones vinculadas a los derechos humanos. Los actores internacionales no jugaron un rol importante en todo este proceso. Finalmente existió un consenso político acerca de la importancia de la reforma (a fin de cuentas, la iniciativa provino de la mayoría en el gobierno), de modo tal que la misma no resultó especialmente problemática. En resumen, podríamos decir que las reformas se debieron al deseo de crear un sistema de justicia civil más eficiente, y no a razones autointeresadas basadas en las presiones de grupos particulares.

\section{Reforma en la justicia penal}

La reforma del proceso penal parece haberse iniciado básicamente a partir de dos preocupaciones fundamentales: crear un sistema más transparente y eficiente introduciendo juicios orales y limitando el rol de los jueces en el proceso. A finales de los 80 , resultaba obvio que el sistema de justicia penal no se encontraba trabajando de modo adecuado. Existían muchos casos por resolver, el acceso a la justicia era muy deficitario, y los jueces decían estar sobrecargados de trabajo. De acuerdo con Jorge Marabotto, el sistema de procedimiento penal en Uruguay es «el peor de toda La-

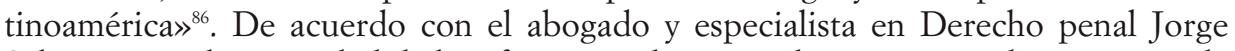
Schurmann, «la necesidad de la reforma en el sistema de justicia penal es compartida por la mayoría de quienes trabajan dentro del sistema: los jueces, los fiscales, y los abogados ${ }^{87}$. A pesar del amplio acuerdo existente acerca de la necesidad de la reforma, varios grupos se mostraron contrarios al contenido de la propuesta de reforma, lo cual dio lugar a un intenso debate académico-legal.

Las preocupaciones económicas -i. e., realizar la reforma del sistema de justicia penal con el objeto de atraer inversiones extranjeras- no parecen haber jugado un rol importante en estos intentos de reforma ${ }^{88}$. Esto no resulta del todo sorprendente, dado que Uruguay ha llevado adelante un proceso de reformas económicas muy lento, en comparación con otros países de la región ${ }^{89}$. De todos modos, un sistema de justicia penal más eficiente hubiera beneficiado a la economía. Las organizaciones de derechos humanos tampoco han estado impulsando reformas de este tipo ${ }^{90}$. De hecho, ha habido un

86. Comunicación personal con Jorge A. Marabotto.

87. Comunicación personal con Jorge P. Pereira Schurmann.

88. Resumen de la evidencia encontrada después de realizar alrededor de una treintena de entrevistas en la ciudad de Montevideo, en el período marzo-abril de 2001. Para más detalles, ver Apéndice 1.

89. Preguntado al respecto, el economista Romero Pérez, del CLAEH, puntúa a Uruguay con un 7 -en una escala de 0 a 10- en la cual Chile merece un 9 y Argentina un 8. Comunicación personal con Romero Pérez.

90. De acuerdo con la información obtenida a partir de entrevistas con académicos y representantes de organizaciones de derechos humanos en agosto de 2000, en Montevideo. Para más detalles, ver Apéndice 1. 
bajo involucramiento civil en estas reformas. En palabras de la Dra. Lilia Ferro Clérico, «la reforma del procedimiento penal... no implicó discusión pública alguna. Punto»" La reforma no puede verse entonces como el resultado de presiones externas frente al gobierno.

Finalmente, y a diferencia de lo ocurrido en Argentina y en Chile, la preocupación sobre cuestiones referidas a la seguridad tampoco parece haber jugado un rol central en la promoción de las reformas. Esto no resulta sorprendente dado que las tasas de criminalidad en Uruguay resultaban relativamente bajas comparadas con las de los países vecinos, y a pesar del creciente desempleo de los últimos años. En resumen, tentativamente podríamos decir que la motivación para la reforma al procedimiento penal provino más de una preocupación general sobre la actuación del sistema, que de presiones específicas vinculadas con temas económicos u otros relacionados con los derechos humanos. Las agencias internacionales no estuvieron involucradas en el área de la reforma penal en Uruguay ${ }^{92}$.

Por qué prosperó la reforma en el procedimiento civil y no la reforma del procedimiento penal

Dado que el sistema de justicia penal en Uruguay se encontraba (ise encuentra!) afectado por muchos de los mismos problemas que afectan al sistema civil, surge la pregunta de por qué las reformas prosperaron en una de tales áreas y no en la otra. Una clave para entender el éxito de la reforma civil es que la misma contaba con un pleno respaldo por parte de la Corte Suprema. Varios de los redactores de la misma, incluyendo a los doctores Marabotto y Torello, eran de hecho miembros de la Corte. Además, resulta más fácil modificar el sistema civil que el penal, dado que el primero involucra a menos actores. El mismo requiere la presencia de un juez y un abogado, mientras que el proceso penal requiere la presencia de dos jueces, fiscales y defensores ${ }^{33}$. Finalmente, el procedimiento de reforma civil requiere menos recursos que el de reforma penal, cuando -según las entrevistas realizadas- los «recursos sobraban» en 1989 mientras que resultaban mucho más escasos en 1998, debido a la crisis económica9 ${ }^{94}$.

De modo significativo, éstos son precisamente los factores que varios informantes identifican como claves, a la hora de explicar el fracaso de la reforma en la justicia penal, diez años después: 1) falta de apoyo dentro del propio poder judicial; 2) carencia de un consenso y una voluntad políticas; y 3) una falta de recursos financieros.

En primer lugar, varios académicos y expertos legales han señalado las resistencias internas del propio poder judicial. En particular, algunos de los miembros de la Corte Suprema se habrían opuesto a las reformas a partir del temor de que podrían perder

91. Comunicación personal con Lilia E. Ferro Clérico, Montevideo, 29 de marzo de 2001.

92. Ver Biebesheimer (2001); DOMingo (2001); Ford Fundation (2002); World BANK (2002).

93. Comunicación personal con Jorge P. Pereira Schurmann.

94. Comunicación personal con Jorge Marabotto. 
poder en manos de los fiscales ${ }^{95}$. Marabotto está de acuerdo en que «muchos jueces temían perder poder», y sostiene también que «muchos jueces se oponían al nuevo sistema porque pensaban que iba a incrementar los poderes del Ejecutivo» (debido al nuevo rol del fiscal, que administrativa, aunque no técnicamente, depende del gobierno). De todos modos Marabotto rechaza de modo enfático la crítica según la cual la principal resistencia a la reforma provino de la propia Corte Suprema: «Esto es una mentira. Absolutamente». Él mismo un miembro de la Corte, Marabotto se encontraba decididamente en favor de la reforma ${ }^{96}$.

Parece haber un acuerdo más general en torno de la falta de voluntad política para llevar adelante la reforma. Inicialmente, existía un acuerdo entre los dos principales partidos políticos del país (los colorados y los blancos) para impulsar la reforma, pero las cosas se complicaron cuando cambiaron las fuerzas políticas tras la aprobación de la ley en 1997. De acuerdo con Schurmann, los cambios en las fuerzas políticas crearon «un consenso contra la implementación de la ley», que incluyó a la propia cabeza del gobierno, encargada de llevarla adelante ${ }^{97}$. Miranda está de acuerdo en la existencia de una falta de «voluntad política» para implementar la reforma. Él piensa que los reformadores creyeron que era posible impulsar a la misma rápidamente -en su opinión «un severo error de cálculo»- pero luego el balance de fuerzas cambió. Miranda agrega, además, que hubo una falta de apoyo técnico a la misma, en particular desde la Facultad de Derecho, a lo que se debe agregar una falta de apoyo económico ${ }^{98}$.

Finalmente, la carencia de recursos es citada, habitualmente, como un obstáculo importante frente a las reformas ${ }^{99}$. Marabotto, actual presidente de la Corte Suprema, insiste en que él en más de una ocasión debió implorar al poder ejecutivo y al ministro de Finanzas por más recursos, sosteniendo que una vez aprobada la ley ella se implementaría con todo cuidado. Sin embargo, no fue escuchado ${ }^{100}$. De acuerdo con el economista Romeo Pérez, Uruguay sufrió una crisis económica profunda en los 90, que afectó al presupuesto afectado a los distintos sectores del Estado, incluyendo al poder judicial. Desde su punto de vista, el argumento relacionado con la carencia de recursos es real ${ }^{101}$.

Tal vez esta carencia de recursos económicos nos esté señalando, en última instancia, la falta de voluntad política necesaria para llevar adelante la reforma. De hecho, hechar las culpas a la falta de recursos aparece como una excusa conveniente para el gobierno. Ya sea que uno opte por una visión más o menos cínica al respecto, lo cierto es que

95. Entre los académicos que sostienen esta postura se encuentran Schurmann, Miranda y Rueco.

96. Comunicación personal con Jorge A. Marabotto.

97. Comunicación personal con Jorge P. Pereira Schurmann.

98. Comunicación personal con Javier Miranda, Montevideo, 3 y 5 de abril de 2001.

99. De acuerdo con Schurmann, Miranda y otros varios académicos, los obstáculos fueron primordialmente económicos, más que políticos. Luis Torello considera que dos de los principales factores que explican el fracaso de la reforma fueron la falta de voluntad política y la falta de apoyo económico. Comunicación personal con Luis Torello, Montevideo, 9 de abril de 2001.

100. Comunicación personal con Jorge A. Marabotto.

101. Comunicación personal con Romeo Pérez. 
desde el momento en que se aprobó la reforma, en 1998, y hasta la fecha, se han producido cambios importantes en la constelación del poder. Sanguinetti, el presidente que nombró a Peri Valdez como fiscal general (y que como tal presidió uno de los intentos de reforma), claramente favoreció las reformas. El actual presidente Jorge Battle (que asumió en el año 2000), por el contrario, parece no preocuparse demasiado por las mismas. Y, tal como señala Ferro Clérico, en última instancia, el poder de la «bolsa» reside en la legislatura, que es la que aprueba el presupuesto preparado por el Ejecutivo. Las constelaciones políticas existentes tanto como el control presupuestario resultan factores importantes, a tener en cuenta, a la hora de explicar el fracaso de las reformas impulsadas en relación con la Corte Suprema.

Las reformas de la Corte Suprema

El mismo año en que se aprobó la reforma al proceso penal aparecieron dos propuestas destinadas a reformar la Corte Suprema. En primer lugar encontramos una propuesta que sugería establecer garantías constitucionales para la independencia financiera del poder judicial. La propuesta estaba basada en la amplia insatisfacción existente en torno al modo en que se distribuía el presupuesto judicial. Tradicionalmente, la Corte Suprema preparaba el presupuesto, que luego era aprobado por el poder ejecutivo, antes de pasar al Parlamento. De acuerdo con Ferro Clérico, «el Ejecutivo recorta y recorta y recorta» de modo tal que el presupuesto finalmente presentado ante la Asamblea General para su aprobación mayoritaria resulta siempre «notablemente inferior» al presupuesto original ${ }^{102}$. Como resultado de dicha situación, la rama judicial padeció de modo permanente la falta de recursos. Todos coincidían, entonces, en la necesidad de promover una reforma capaz de asegurar la independencia económica de la justicia. La propuesta realizada entonces tuvo como objetivo principal asegurar esta independencia, haciendo posible que el presupuesto fuera directamente al Parlamento, sin tener que pasar antes por el Ejecutivo. De acuerdo con el proceso rígido de reforma, propio de la Constitución uruguaya, la propuesta de cambio en favor de la Corte debía ser sometida a un referéndum popular. El mismo se celebró en el año 2000, y el resultado fue de un 46-47, por lo que no obtuvo la mayoría de los votos necesaria para ratificar la enmienda.

En marzo de 2000, se presentó otro proyecto de reforma, destinado a ampliar el número de miembros de la Corte de 5 a 9 miembros, y dividir la Corte en tres salas especializadas -siguiendo así el modelo de la Corte Suprema chilena, recién renovada-. Esta propuesta se encuentra aún bajo estudio en el Congreso. Las opiniones al respecto están divididas. Los especialistas legales involucrados en la reforma sostienen que la Corte existente era pequeña y que se encontraba sobrecargada de trabajo. Al incrementar el número de jueces y dividir las tareas de acuerdo a su especialización -afirmaronpodría incrementarse la eficiencia y profesionalidad de los tribunales. El especialista

102. Comunicación personal con Lilia E. Ferro Clérico. 
legal y ex juez de la Corte, Dr. Torello, es uno de los que apoyan la reforma ${ }^{103}$. De todos modos, no todos están de acuerdo con la misma -incluyendo algunos jueces que actuaron antes en la Corte-. La Dra. Balbela, también ex jueza de la Corte, considera que la Corte puede funcionar bien con su número actual. En su opinión, existen otras cuestiones más importantes y más relevantes dentro del sistema judicial uruguayo, que deben atenderse con antelación a cualquier reforma en torno a la organización y tamaño de la Corte ${ }^{104}$. En resumen, hasta el momento no se han realizado cambios de importancia en la Corte Suprema uruguaya.

\section{Por qué han fracasado las reformas a la Corte Suprema}

¿Cuáles fueron los principales factores que motivaron estos intentos de reforma dirigidos a asegurar mayor independencia e incrementar el número de miembros de la Corte Suprema? ¿Y por qué fracasaron? El impulso para garantizar la independencia financiera del poder judicial surgió de la propia Corte -obviamente motivada por razones egoístas-. Los jueces uruguayos, durante mucho tiempo, consideraron que tenían las manos atadas y eran incapaces de ejercer adecuadamente sus tareas, dadas las restricciones presupuestarias que debían afrontar. De todos modos, no se dio la movilización política y popular necesaria para asegurar el éxito de estas propuestas reformistas. Aparentemente la falta de apoyo popular a las mismas tuvo que ver con dos causas interrelacionadas. En primer lugar, los políticos que apoyaban la reforma no realizaron una campaña pública suficiente en favor de la misma. Aunque, ocasionalmente, la reforma era mencionada en los medios de comunicación, los canales de TV nacionales le dedicaron poco o nada de espacio. En segundo lugar, los esfuerzos destinados a promover estas reformas se encontraron con una ciudadanía poco interesada en las mismas. Históricamente, el poder judicial uruguayo ha aparecido como marginal, y ha recibido poco atención en los medios, a la vez que ha gozado de una baja popularidad. El resultado de la suma de estos factores fue la poca atención en los medios, primero, y luego la poca atención pública sobre la propuesta de cambio. El fracaso tuvo que ver, así, con una combinación de falta de apoyo político y falta de participación popular ${ }^{105}$.

La otra propuesta de reforma se detuvo por razones diferentes. El proyecto de incrementar el número de miembros de la Corte, dividiéndola en salas especializadas, fue objeto de intensos debates académicos desde $1985^{106}$. Sin embargo, no hubo una mención seria de la Corte Suprema durante las discusiones sobre la reforma constitucional en 1996. El debate se desató sólo dos años después. La propuesta inicial fue la de incrementar el número de miembros de la Corte y dividir a la misma en salas especializadas, tendiendo a incrementar la eficiencia y reducir la sobrecarga de trabajo de los jueces.

103. Comunicación personal con Luis Torello.

104. Comunicación personal con Jacinta Balbela.

105. Urioste y Balbela, por ejemplo, sostienen este punto de vista.

106. Comunicación personal con Javier Miranda. 
El lanzamiento de la propuesta se dio en 1998, coincidiendo con la campaña presidencial en donde, por primera vez en la larga historia de bipartidismo uruguayo, apareció un nuevo partido, el Frente Amplio (una coalición de izquierdas formada en 1971) que obtuvo un triunfo inesperado en Montevideo (en donde reside la mitad de la población uruguaya, de 3,5 millones) y casi un tercio de los votos a lo largo del país. El hecho de que el tradicional bipartidismo estuviera dejando lugar a la aparición de una tercera fuerza, señaló a los miembros de los partidos Blanco y Colorado que ya no podían controlar la escena política y que, por lo tanto, no podían seguir ejerciendo su habitual control sobre la Corte Suprema ${ }^{107}$. De acuerdo con los procedimientos de designación existentes, los jueces de la Corte Suprema son nombrados por períodos de diez años y requieren para su designación del voto de las dos terceras partes de la Asamblea General. En la práctica, esto significa que con el cambio en las fuerzas políticas producido en 1998, los dos partidos tradicionales necesitarían del apoyo de los partidos minoritarios (Frente Amplio y Nuevo Espacio) a la hora de nombrar a los nuevos jueces. El incremento en el número de miembros de la Corte, entonces, podría implicar un cambio sustantivo en la composición de la misma. Uno podría especular, entonces, que la reforma no va a obtener el apoyo parlamentario debido, por parte de los partidos Blanco y Colorado.

En resumen, ha habido intentos para asegurar la independencia judicial e incrementar el número de miembros de la Corte, y ambos han fracasado. En el primer caso ello se debió a la falta de apoyo popular en el referéndum, y en el segundo debido a la falta de apoyo político.

\section{Conclusiones}

Este análisis de los procesos de reforma judicial en Argentina, Chile y Uruguay durante los 90, ha demostrado que los factores que han motivado las reformas en los códigos de procedimiento han sido, en cada caso, sustancialmente diferentes de los que han impulsado las reformas constitucionales -reformas que implicaron modificaciones en cuanto a la independencia y el poder de la Corte Suprema-. Más aún, este análisis ha mostrado que existen muchos elementos comunes entre lo ocurrido en Argentina y en Chile. En cambio, Uruguay ha seguido, aparentemente, un camino diverso al de sus vecinos, tanto en las iniciativas reformistas que han existido como en los resultados finalmente obtenidos.

En los casos de Chile y Argentina, hemos visto que los esfuerzos en pos de reformas realizados después de comenzada la transición democrática han estado íntimamente vinculados con el deseo de restaurar la legitimidad de la Magistratura tras su fracaso para impedir abusos en materia de derechos humanos, durante las dictaduras

107. Tradicionalmente, y desde los años 20-30, la Corte Suprema se compuso de tres miembros simpatizantes del Partido Colorado y dos simpatizantes del Partido Blanco, o al revés. Comunicación personal con Alberto Pérez Pérez. 
respectivas. Este punto resulta particularmente notable en el caso de Chile (donde fracasaron los dos primeros intentos reformistas realizados durante el gobierno de Alwyn $)^{108}$. Un segundo factor que ha motivado las reformas en la justicia penal ha sido el deseo de modernizar y reformar los tribunales, tornándolos más transparentes, para atraer también la inversión extranjera. La evidencia encontrada nos permite sugerir que las reformas fueron motivadas, al menos en parte, por cuestiones económicas. Un tercer factor que ha estado detrás de la producción de las reformas ha sido el deseo de fortalecer al sistema judicial, para poder combatir entonces tasas de criminalidad crecientes, y afrontar así el problema de la seguridad pública.

En resumen, las reformas en los códigos de procedimiento de Chile y Argentina han sido realizadas con el objeto de atender, al mismo tiempo, una diversidad de problemas, derivados del doble proceso simultáneo de democratización y liberalización económica. Un poder judicial más eficiente y transparente resultaba esencial para resolver el problema del abarrotamiento de causas en manos de la justicia; combatir el incremento en las tasas de criminalidad; afrontar la creciente preocupación pública con temas vinculados a la seguridad; y favorecer un ambiente más seguro para las inversiones extranjeras. En ambos países, estas reformas han sido fundamentalmente diseñadas e impulsadas por académicos en cooperación con políticos nacionales.

Con respecto a las reformas en los procedimientos penales, los resultados se han dado de una forma mucho más lenta que la esperada. En Argentina, todavía se advierte un gran retraso en la resolución de las causas judiciales, y un gran número de vacantes judiciales por completar. Este retraso parece deberse, en parte al menos, a la falta de voluntad política y de compromiso para la implementación de las reformas. En Chile, por el contrario, las reformas parecen haberse dado conforme a lo esperado, aun cuando el Código de Justicia Penal no ha sido aún plenamente implementado. Según parece, el compromiso político en favor de tales reformas ha sido más fuerte que el que ha caracterizado al proceso de reformas en Argentina ${ }^{109}$.

Uruguay, uno de los tres países examinados, es el que ha tenido menos éxito en el área de las reformas judiciales. La (fracasada) experiencia reformista en Uruguay, tendente a modificar el Código de Procedimiento Penal, en 1998, no pareció estar motivada por preocupaciones económicas, ni por razones vinculadas a los derechos humanos, ni a una necesidad de afrontar el problema de una criminalidad creciente. Esto puede explicarse por el hecho de que en Uruguay no ha habido una reestructuración económica significativa; por el hecho de que el poder judicial nunca fue visto como cómplice de las estructuras militares, tal como ocurría en Argentina y en Chile; y por

108. Adviértase, de todos modos, que los movimientos en pro de los derechos humanos han jugado un rol relativamente marginal en la producción de estas reformas. En Chile, sólo una organización no gubernamental involucrada en cuestiones de derechos humanos, CODEPU, se ha mostrado activa en la promoción de reformas en la justicia penal, dado la amplitud de sus objetivos. En Argentina, el Centro de Estudios Legales y Sociales (CELS), ha realizado investigaciones en torno a las consecuencias de la reforma pero no se ha mostrado activo en la promoción de la misma.

109. Una discusión más detallada acerca del fracaso de las reformas judiciales en Argentina, y su mayor éxito en Chile, en Prillaman (2000). 
el hecho de que las tasas de criminalidad han sido mucho más bajas aquí que en los países vecinos. La evidencia encontrada nos permite decir que muchos de los miembros del poder judicial, tanto como académicos y políticos, sólo aparecían preocupados por modernizar y mejorar la eficiencia de la justicia. El fracaso de estas reformas demuestra la falta de voluntad política de utilizar los recursos económicos requeridos por estas iniciativas. El deseo de crear un sistema de justicia civil eficiente y efectivo también apareció como un factor importante, detrás de la exitosa reforma en los procedimientos civiles, en un momento en donde los recursos económicos eran mayores, y existía además un mayor acuerdo tanto político como judicial, en torno de la importancia de la reforma.

Si nos concentramos ahora en las reformas sobre la Corte Suprema, podríamos decir que, en los tres países estudiados, la iniciativa reformista fue motivada por razones meramente autointeresadas. Los cambios impulsados por Menem en 1994 pueden leerse como una forma de negociar el apoyo de la oposición hacia una reforma constitucional capaz de permitirle la reelección, en 1995. En Chile, la ley destinada a reformar la Corte Suprema, en 1997, fue el resultado de un apurado compromiso político entre la izquierda y la derecha, disparado por un escándalo de corrupción, y posiblemente también por el deseo de la ministra de Justicia de asegurarse una mayor popularidad a partir de la reforma.

Aunque tanto en Argentina como en Chile ha habido un significativo incremento en la independencia formal de los jueces, la forma en que esto se ha traducido a la práctica ha sido diferente en ambos países. La naturaleza del compromiso político con las reformas ha llevado, en Chile, a que las dos fuerzas políticas principales se alinearan detrás de la promoción de cambios a nivel de la Corte Suprema. El resultado ha sido la promoción de cambios sustantivos en la composición del tribunal principal, lo que parece haber producido resultados positivos, especialmente en el área de los derechos humanos. Por el contrario, por la falta de compromiso con las reformas que puede advertirse en Argentina, los cambios sobre la Corte Suprema han seguido un ritmo muy lento. De allí que no sorprenda el hecho de que la Corte Suprema no haya alterado significativamente su comportamiento desde 1994, cuando se produjeron las reformas ${ }^{110}$.

Nuevamente, Uruguay parece el «perdedor» en este tema. La propuesta destinada a asegurar un financiamiento independiente para la Corte Suprema provino de la misma Corte. Falló, en todo caso, debido a la falta de apoyo político tanto como público. El intento de expandir la Corte Suprema y convertirla en un tribunal más especializado fue impulsado inicialmente por los dos partidos tradicionales (los blancos y los colorados). Este análisis ha sugerido que los partidos renegaron de la reforma al advertir que deberían tomar en consideración a la oposición en la designación de jueces para la Corte Suprema (debido a la exigencia de dos tercios de votos para la aprobación senatorial) cuando el Frente Grande, inesperadamente, obtuvo casi un tercio de

110. Una discusión más detallada de los efectos de las reformas al nivel de las Cortes Supremas en Argentina, Chile, y Uruguay, en SKAAR (2002). 
los votos en la elección de 1998. El resultado final de la propuesta de reforma todavía está por verse.

En resumen, estos tres casos han demostrado que las reformas en los procedimientos penales se han visto impulsadas por causas complejas y relacionadas entre sí, que involucraron planes de largo plazo y múltiples acuerdos y compromisos entre diferentes sectores del gobierno durante un período extenso. Las reformas sobre la Corte Suprema, por el contrario, parecen estar motivadas por preocupaciones políticas más estrechas, que involucran a menos actores.

Finalmente, el análisis ha demostrado que en los tres países, las reformas procedimentales tanto como las realizadas al nivel de las Cortes Supremas han sido promovidas a partir de las fuerzas locales. El involucramiento de las agencias internacionales en todo este proceso ha sido muy limitado. Esto distingue a lo ocurrido en los tres países examinados, de lo ocurrido en otras naciones latinoamericanas, en donde tales reformas se han visto significativamente influidas por la participación de las agencias externas.

Tomando en cuenta el diferente rol jugado por los actores internacionales en estos procesos de reforma, un futuro análisis deberá demostrar si las causas nacionales que motivaron las reformas en Chile, Argentina y Uruguay fueron las mismas que estuvieron presentes en otros países de América Latina. Conociendo los detalles de estos procesos de reforma en otros países, podremos discernir si existen parámetros sistemáticos capaces de explicar los mismos. Del mismo modo, dicha investigación permitirá construir una teoría más sistemática que la actualmente disponible, en relación con las reformas judiciales.

\section{Apéndice 1: Entrevistas (por orden cronológico)}

\section{CHILE}

Maurico Duce, profesor de Derecho, Universidad Diego Portales, Santiago, 5 de mayo de 2000.

Nicolás Espejo, profesor de Derecho, Universidad Diego Portales, Santiago, 9 de mayo de 2000.

Juán Enrique Vargas, profesor de Derecho, Universidad Diego Portales, Santiago, 11 de mayo de 2000.

Ximena Torcanal, profesora de Psicología, ARCIS, Santiago, 11 de mayo de 2000.

Jorge Correa Sutil, profesor de Derecho, Universidad Diego Portales, Santiago, 15 de mayo de 2000.

Jorge Mera, profesor de Derecho, Universidad Diego Portales, Santiago, 16 de mayo de 2000.

Cristián Riego, profesor de Derecho, Universidad Diego Portales, Santiago, 16 de mayo de 2000.

Yuri Gahona, MA estudiante de Sociología, Universidad Alberto Hurtades, 22 de mayo de 2000. 
Raúl Lopez, Santiago, 23 de mayo de 2000.

Julián Muñoz Torres, profesor de Derecho, Universidad de Chile, Santiago, 24 de mayo de 2000.

Mario Torres Labraña, juez, 29a Corte Civil de Santiago, 25 de mayo de 2000.

Eduardo Contreras, abogado de derechos humanos, Santiago, 25 de mayo de 2000.

Cristián Bustos, editor, La Segunda (El Mercurio), Santiago, 25 de mayo de 2000.

Mario Garrido Montt, juez de la Corte Suprema y presidente del Tribunal Calificador de Eleciones de Chile, profesor de Derecho, Universidad Diego Portales, Santiago, 29 de mayo de 2000.

Jorge Mario Saavedra, abogado, Santiago, 29 de mayo de 2000.

Héctor Salazar, abogado, miembro de la Mesa de Diálogo, Santiago, 30 de mayo de 2000.

José Zalaquett, abogado, miembro de la Mesa de Diálogo, miembro de la Comisión Rettig y profesor de Derecho, Santiago, 7 de junio de 2000.

Hugo Frühling, abogado y profesor, Departamento de Ciencia Política, Universidad de Chile, Santiago, 8 de junio de 2000.

Mireya García, Vicepresidenta, AFFDD, Santiago, 9 de junio de 2000.

Víctor Espinoza, director general, CODEPU, Santiago, 9 de junio de 2000.

Gastón Gómez, profesor de Derecho, Universidad Diego Portales, Santiago, 12 de junio de 2000.

Roderigo de la Barra, Academia Judicial, Santiago, 13 de junio de 2000.

Carlos Valdivezo, gerente, Fundación Paz Ciudadana, Santiago, 13 de junio de 2000.

Verónica Reyna, presidenta, FASIC, Santiago, 15 junio de 2000.

Roberto Garettón, abogado, miembro de la Mesa de Diálogo, Santiago, 15 de junio de 2000.

Andrés Baytelman, profesor de Derecho, Universidad Diego Portales, Santiago, 16 de junio de 2000.

Felipe Gonzales, profesor de Derecho, Universidad Diego Portales, Santiago, 21 de junio de 2000.

Felipe Caballero y Nelson Cortez (entrevista conjunta), abogado y asistente respectivamente, Santiago, 22 de junio de 2000.

Nelson Caucoto, abogado de derechos humanos, Santiago, 23 de junio de 2000.

Lionel N. Acuña Faúndez, ex coronel Carabineros, analista político, Santiago, 23 de junio de 2000.

Raphael Blanco, abogado (designado por la Ley de Reforma de la Corte Suprema), Santiago, 27 de junio de 2000.

Carlos Peña, decano, Universidad Diego Portales, Santiago, 27 de junio de 2000.

Carlos Cerda, juez y presidente de la $5^{a}$ Cámara de Apelaciones de Santiago, Santiago, 28 de junio de 2000.

Hugo Gutiérrez, abogado, CODEPu, Santiago, 29 de junio de 2000.

Alberto Chaigneau, juez de la Corte Suprema, Cámara de Justicia Penal, Santiago, 29 de junio de 2000.

Patricia Silva, presidenta, AFEP, Santiago, 30 de junio de 2000. 
ARGENTINA

Alicia Herbón, secretaria de la Coordinación y miembro de la Comisión de Educación, APDH, Buenos Aires, 17 de julio de 2000.

Horacio Ravenna, abogado y miembro de la Comisión Internacional, APDH, Buenos Aires, 17 de julio de 2000.

Carlos Zamorano, co-presidente, Liga Argentina por los Derechos Humanos, Buenos Aires, 18 de julio de 2000.

María Cristina Caiati, directora del Centro de Documentación Center, CELS, Buenos Aires, 18 de julio de 2000.

Nora de Cortiñas, presidenta, Madres de Plaza de Mayo, Línea Fundadora, Buenos Aires, 19 de julio de 2000.

Adrián Ventura, abogado, profesor de Derecho Constitucional y periodista, La Nación, Buenos Aires, 20 de julio de 2000.

Sergio Dario Di Gioia, APDH, abogado y miembro de la Comisión Jurídica y del Consejo de la Presidencia, catedrático de Derecho en la Universidad de Buenos Aires, 21 de julio de 2000.

Martín Abregú, director ejecutivo, Centro de Estudios Legales y Sociales (CELS), Buenos Aires, 24 de julio de 2000.

Francisco Pullen, Poder Ciudadano, Buenos Aires, 24 de julio de 2000.

Carlos March, director ejecutivo, Poder Ciudadano, Buenos Aires, 24 de julio de 2000.

Juan de Wandelaer, SERPAJ, Buenos Aires, 24 de julio de 2000.

Alberto Bovino, asesor del Ministerio de Justicia y Derechos Humanos, Buenos Aires, 25 de julio de 2000.

Taty Almeida, Madres de Plaza de Mayo, Línea Fundadora, Buenos Aires, 30 de julio de 2000.

Carlos Alberto Vallefín, abogado y relator en la Corte Suprema de Justicia, con el juez Fayt, Buenos Aires, 31 de julio de 2000.

Daniel Alberto Sabsay, abogado y profesor de Derecho Constitucional, Universidad de Buenos Aires, Buenos Aires, 1 de agosto de 2000.

Pastor José de la Luca, director ejecutivo y Pastor Arturo, Movimiento Ecuménico por los Derechos Humanos, Buenos Aires, 1 de agosto de 2000.

Mabel Gutiérrez, presidenta, Familiares de Desaparecidos y Detenidos por Razones Políticas, Buenos Aires, 1 de agosto de 2000.

Alberto R. Dalla Via, profesor de Derecho Constitucional, vicedirector, Universidad de Belgrano, Buenos Aires, 2 de agosto de 2000.

Sofía Tiscornia, asesora de la Defensoría del Pueblo, Buenos Aires, 3 de agosto de 2000.

Roberto Saba, profesor de Derecho, Universidad de Palermo, Buenos Aires, 3 de agosto de 2000.

Claudio Marcelo Kiper, juez de la Cámara de Apelaciones y miembro del Consejo de la Magistratura, Buenos Aires, 4 de agosto de 2000. 
Christian Courtis, profesor de Derecho, Universidad de Buenos Aires y asesor del juez Maier del Tribunal Superior de la Ciudad de Buenos Aires, 4 de agosto de 2000.

Julio B. J. Maier, juez, Tribunal Superior de Justicia en la Ciudad de Buenos Aires, Buenos Aires, 4 de agosto de 2000.

Alba R. Lanzillotto, secretaria, Abuelas de Plaza de Mayo, Buenos Aires, 7 de agosto de 2000.

Alberto P. Pedroncini, abogado de derechos humanos, Buenos Aires, 8 de agosto de 2000.

Horacio Cattani, juez, Cámara de Apelaciones Buenos Aires, Buenos Aires, 9 de agosto de 2000.

Adolfo Luis Bagnasco, juez, Cámara de Apelaciones Buenos Aires, Buenos Aires, 9 de agosto de 2000.

Mercedes Miroño, vicepresidenta, Madres de Plaza de Mayo, Buenos Aires, 9 de agosto de 2000.

Jaime Malamud-Goti, consejero legal del presidente Alfonsín, profesor de Derecho en la Universidad de Buenos Aires, varias entrevistas de julio-agosto de 2000.

Catalina Smulovitz, Universidad Di Tella, Buenos Aires, 22 de agosto de 2000.

Patricia Valdez, CELS, Buenos Aires, 23 de agosto de 2000.

\section{URUGUAY}

Eduardo G. Esteva, director general, Centro de Documentación y Estudios Constitutionales de Uruguay, Montevideo, 17 de agosto de 2000.

José Pedro Rilla, CLAEH (Centro Latinoamericano de Economía Humana, Instituto Universitario), Montevideo, 17 de agosto de 2000.

Raúl Zibechi, periodista, Brecha, Montevideo, 26 de marzo de 2001.

Aldo Marchesi, CEIL (Centro de Estudios Interdisciplinarias Latinoamericanas), Montevideo, 27 de marzo de 2001.

Jorge A. Marabotto, ex juez, Corte Suprema, Montevideo, 28 de marzo de 2001.

Oscar Destouet, profesor de Historia y voluntario en la Comisión para la Paz, Grupo de Madres y Familiares de Uruguay, Montevideo, 28 de marzo de 2001.

Lilia E. Ferro Clérico, Corte Suprema, Montevideo, 29 de marzo de 2001.

Felipe Michelini, miembro del Congreso y profesor de Derechos Humanos, Universidad de la República, Montevideo, 17 de agosto de 2000 y 29 de marzo de 2001.

Gonzalo Fernández, asesor legal de Tabaré Vásquez (presidente del Frente Amplio) y miembro de la Comisión para la Paz, Montevideo, 30 de marzo de 2001.

Asociación de Madres y Familiares de Detenidos Desaparecidos Uruguayos, entrevistas grupales, Montevideo, 18 de agosto del 2000 y 30 del marzo de 2001.

Federico Fasano, abogado y editor principal, La República, Montevideo, 30 de marzo de 2001.

Alberto Pérez Pérez, profesor de Derecho, Facultad de Derecho, Universidad de la República, Montevideo, 2 de abril de 2001. 
Eduardo Pirotto, Madres y Familiares del Uruguay, coordinador de la Comisión para la Paz, Montevideo, 2 de abril de 2001.

Carlos Demasse, CEIL, Montevideo, 2 de abril de 2001.

Javier Miranda, abogado de derechos humanos, coordinador de la Comisión para la Paz, Montevideo, 3 y 5 de abril de 2001.

María del Carmen Rueco, coordinador de la Administración, Corte Suprema, Montevideo, 3 de abril de 2001.

Fernando Urioste, profesor de Derecho Penal, Facultad de Derecho, Universidad de la República, Montevideo, 4 de abril de 2001.

Estela Jubette, Juez de $1^{a}$ Instancia Corte Civil, Montevideo, 4 de abril del 2001.

Romeo Pérez, CLAEH, Montevideo, 4 de abril de 2001.

Jorge P. Pereira Schurmann, abogado y especialista en Justicia Penal, Montevideo, 4 de abril de 2001.

Guillermo Payseé, abogado y coordinador SERPAJ, Montevideo, 4 de abril de 2001.

Carlos Ramela, asesor legal del presidente Batlle y miembro de la Comisión para la Paz, Montevideo, 5 de abril de 2001.

Álvaro Rico, analista político, CEI, Montevideo, 6 de abril de 2001.

Jacinta Balbela, ex miembro de la Corte Suprema, Montevideo, 6 de abril de 2001.

Luis Torello, ex miembro de la Corte Suprema, Montevideo, 9 de abril de 2001.

Pablo Chargoñia, PIT-CNT, Montevideo, 9 de abril de 2001.

José Claudio Wiliman, coautor de la Ley de Caducidad y miembro de la Comisión para la Paz, Montevideo, 10 de abril de 2001.

\section{BIBLIOGRAFÍA}

BECKER, David G. Latin America: Beyond Democratic Consolidation. Journal of Democracy, 1999, $\mathrm{n}^{\circ} 10(2)$, pp. 138-151.

BICKFORD, Louis N. Democracy, Stakeholdership, and Public Policy-Making in Chile, 1990-1997: the Case of Judicial Reform. Paper leído en 1998 en el encuentro de la Latin American Studies Association, 24-26 de septiembre, Chicago.

BIEBESHEIMER, Christina. Justice reform in Latin America and the Caribbean: the IDB perspective. En Domingo, P. y Sieder, Rachel (eds.). Rule of Law in Latin America: The International Promotion of Judicial Reform. London: Institute of Latin American Studies, University of London, 2001

Borx, Charles. Choosing Electoral Rules. Structural Factors or Political Calculations. Paper leído en el Annual Meeting of the American Political Science Association, 28-31 de agosto, Washington, DC, 1997.

BusCalgia, Edgardo; DaKolias, Maria y RatclifF, William. Judicial Reform in Latin America: A Framework for National Development. Stanford, California: Stanford University Press, 1995.

CELS (Centro de Estudios Legales y Sociales). Informe Anual 1995. Buenos Aires, Argentina: Eudeba, 1995.

CoRREA SuTIL, Jorge. The Judiciary and the Political System in Chile: The Dilemmas of Judicial Independence During the Transition to Democracy. En STOTZKY, I. P. (ed.). Transition to Democracy in Latin America: The Role of the Judiciary. Boulder, Colorado: Westview Press, 1993. 
Dakolias, Maria. A Strategy for Judicial Reform: The Experience in Latin America. Virginia. Journal of International Law, 1995, $\mathrm{n}^{\circ} 36$ (1), pp. 167-231.

- The Judicial Sector in Latin America and the Caribbean. Elements of Reform. Washington, DC: The World Bank, 1996.

De la BarRa, Carlos Rodrigo. Hegemonies and Counterhegemonies in the Institutional Reconstruction of Democracy in Chile. Paper leído en el Seminario sobre Globalization, Law and Democracy, Uw Law School, 1997.

- Adversarial vs. Inquisitorial Systems, the Rule of Law, and Prospects for Criminal Procedure Reform in Chile. Journal of Law and the Trade in the Americas, 1999, mayo.

Domingo, Pilar. Judicial Independence and Judicial Reform in Latin America. En ScHEdLeR, A.; Diamond, Larry y Plattner, Marc F. (eds.). The Self Restraining State: Power and Accountability in New Democracies. Boulder, Colorado: Lynne Rienner Publishers, Inc., 1999.

Domingo, Pilar y SIEDER, Rachel (eds.). Rule of Law in Latin America: The International Promotion of Judicial Reform. Londres: Institute of Latin American Studies, University of London, 2001.

DuCE, Mauricio. Criminal Procedural Reform and the Ministerio Publico: Toward the Construction of New Criminal Justice System in Latin America. Juridical Science Master. Tesis presentada en el Stanford Program in International Legal Studies at Stanford Law School, Stanford, 1999.

FInKEL, Jodi. Judicial Reform in Latin America: Market Economies, Self-Interested Politicians, and Judicial Independence. Paper leído en el Annual Meeting of the American Political Science Association, 2-5 de septiembre, Atlanta, 1999.

Ford Foundation. Home Page [http: //www.fordfound.org/]. Ford Foundation, 2002 [citado el 5 de noviembre de 2002].

Frankel, Marvin E. Concerning the Role the Judiciary May Serve in the Proper Functioning of a Democracy. En Stotzky, I. P. (ed.). Transition to Democracy in Latin America: The Role of the Judiciary. Boulder, Colorado: Westview Press, 1993.

FrÜHLING, Hugo (ed.). Judicial Reform and Democratization in Latin America. En AGÜERO, F. y STARK, Jeffrey. Fault Lines of Democracy in Post-Transitional Latin America. Miami: NorthSouth Center Press of the University of Miami, 1998.

- Control Democrático en el Mantenimineto de la Seguridad Interior. Santiago de Chile: Centro de Estudios de Desarrollo, 1998.

Garro, Alejandro M. Nine Years of Transition to Democracy in Argentina: Partial Failure or Qualified Success? Colombia Journal of Transnational Law, 1993, n 31 (1), pp. 1-102.

GEDDES, Barbara. Democratic Institutions as Bargains Among Self-Interested Politicians. Paper leído en el Annual Meeting of the American Political Science Association, octubre, 1990.

- Politician's Dilemma. Building State Capacity in Latin America. Berkeley and Los Angeles, CA: University of California Press, 1994.

Haggard, Stephen y McCubbins, Matthew. Political Institutions and the Determinants of Public Policy: When Do Institutions Matter? Paper leído en UCSD, 1997.

Hammergren, Linn A. The Politics of Justice and Justice Reform in Latin America. Boulder, Colorado: Westview Press, 1998.

Helmke, Gretchen. The Logic of Strategic Defection: Court-Executive Relations in Argentina Under Dictatorship and Democracy. American Political Science Review, 2002, nº 96 (2), pp. 291-303.

JARQUÍn, Edmundo y CARRILlO, Fernando (eds.). Justice Delayed: Judicial Reform in Latin America. Washington, DC: Inter-American Development Bank, 1998. 
KAHN, Paul W. Independence and Responsibility in the Judicial Role. En STOTZKY, I. P. Transition to Democracy in Latin America: The Role of the Judiciary. Boulder, Colorado: Westview Press, 1993.

LARKINS, Christopher M. Judicial Independence and Democratization: A Theoretical and Conceptual Analysis. The American Journal of Comparative Law, 1996, $\mathrm{n}^{\circ} 44$ (4).

Nino, Carlos Santiago. The Debate Over Constitutional Reform in Latin America. Fordham International Law Journal, 1992, n 16 (3), pp. 635-651.

OAS. The Improvement of the Administration of Justice in the Americas, Protection and Guarantees for Judges and Lawyers in Exercise of their Functions: Inter-American Juridical Committee, 1994.

Palermo, Vicente. The Origins of Menemismo. En Brennan, J. P. Peronism and Argentina. Wilmington, DE: Scholarly Resources Inc., 1998.

Plattner, Marc F. Traditions of Accountability. En Schedler, A.; Diamond, Larry y Plattner, Marc F. (eds.). The Self-Restraining State: Power and Accountability in New Democracies. Boulder, Colorado: Lynne Rienner Publishers, Inc., 1999b.

PRILlaman, William C. The Judiciary and Democratic Decay in Latin America. Declining Confidence in the Rule of Law. Westport, Ст: Praeger, 2000.

RIEgo, Cristian. The Chilean Criminal Procedure Reform. Master of Laws, LL.M. Wisconsin: University of Wisconsin Law School, University of Wisconsin, 1997.

RONIGER, Luis. Human Rights Violations and the Reshaping of Collective Identities in Argentina, Chile and Uruguay. Social Identities, 1997, n 3 (2), pp. 221-246.

Roniger, Luis y Sznajder, Mario. The Legacy of Human Rights Violations in the Southern Cone. Argentina, Chile, and Uruguay. New York: Oxford University Press, 1999.

Rosenn, Keith S. The Protection of Judicial Independence in Latin America. The University of Miami Inter-American Law Review, 1987, n 19 (1), pp. 1-35.

SabSaY, Daniel A. y OnAINDIA, José M. La Constitución de los Argentinos. Análisis y comentario de su texto luego de la reforma de 1994. $4^{a}$ edición. Buenos Aires: ERREPAR, S.A., 1998.

SCHWARTZ, Herman. Surprising Success: The New Eastern European Constitutional Courts. En SCHEDleR, A.; DiamOnd, Larry y Plattner, Marc F. (eds.). The Self-Restraining State: Power and Accountability in New Democracies. Boulder, Colorado: Lynne Rienner Publishers, Inc., 1999.

SKAAR, Elin. Judicial Independence: A Key to Justice. An Analysis of Latin America in the 1990s. Tesis doctoral. Los Angeles: Department of Political Science, University of California, Los Angeles, 2002.

Stotzky, Irwin P. (ed.). Transition to Democracy in Latin America: The Role of the Judiciary. Boulder, Colorado: Westview Press, 1993.

Thome, Joseph R. Searching for Democracy: The Rule of Law and the Process of Legal Reform in Latin America. Paper leído en el Workshop of the Instituto Internacional de Sociología Jurídica, 6-7 abril, Oñati, Gipuzkoa, Spain, 1998. http: //darkwing.uoregon.edu/ caguirre/thomepr.html.

Tsebelis, George. Nested Games. Rational Choice in Comparative Politics. Berkeley and Los Angeles, CA: University of California Press, 1990.

VARgas, Juan Enrique Viancos y CORREA Sutil, Jorge. Diagnóstico del sistema judicial chileno. Santiago de Chile: Centro de Desarrollo Jurídico Judicial. Corporación de Promoción Universitaria (CDJ-CPU), 1995.

Vaughn, Robert G. Proposals for judicial reform in Chile. Fordham International Law Journal, 1992, no 16 (3), pp. 577-607. 


\section{6}

WIDNER, Jennifer. Building Judicial Independence in Common Law Africa. En SCHEDLER, A.; Diamond, Larry y PlatTneR, Marc F. The Self-Restraining State: Power and Accountability in New Democracies (eds.). Boulder, Colorado: Lynne Rienner Publishers, Inc., 1999.

World BAnK. Projects, Policies, and Strategies [http: //www4.worldbank.org/sprojects/]. World Bank, 2002 [citado el 5 de noviembre de 2002].

YAMANISHI, David Scott. Judicial Independence and the Rule of Law. The Ineffectiveness of Judicial Independendence Alone as a Path to Development. Paper leído en el Annual Meeting of the American Political Science Association, 2-5 de septiembre, Atlanta, 1999. 